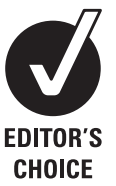

Department of Laboratory Medicine and Pathobiology University Health Network, Toronto, Canada

\section{Correspondence to} Dr Danny Ghazarian, Department of Pathology, Toronto General Hospital, 190 Elizabeth St, Toronto, Ontario M5G2C4, Canada;

Danny.Ghazarian@uhn.on.ca

Accepted 3 January 2010

\title{
Spindle cell melanocytic lesions-part I: an approach to compound naevoidal pattern lesions with spindle cell morphology and Spitzoid pattern lesions
}

\author{
Shachar Sade, Ayman Al Habeeb, Danny Ghazarian
}

\begin{abstract}
Melanocytic lesions show great morphological diversity in their architecture and the cytomorphological appearance of their composite cells. Whereas functional melanocytes reveal a dendritic cytomorphology and territorial isolation, lesional naevomelanocytes and melanoma cells typically show epithelioid, spindled or mixed cytomorphologies and a range of architectural arrangements. Spindling is common to melanocytic lesions, and may be either a characteristic feature or a divergent appearance. The presence of spindle cells may mask the melanocytic nature of a lesion, and is often disconcerting, either because of its infrequent appearance in a particular lesion or its interpretation as a dedifferentiated phenotype. Spindle cell melanocytic lesions follow the full spectrum of potential biological outcomes, and difficulty may be experienced judging the nature of a lesion because of a lack of consistently reliable features to predict biological behaviour. Over time, recognition of numerous histomorphological features that may portend a more aggressive lesion have been identified. However, the translation of these features into a diagnostic entity requires a gestalt approach. Although most spindle cell melanocytic lesions can reliably be resolved with this standard approach, problem areas do exist and cause no end of grief to the surgical pathologist or dermatopathologist. In this review, the authors present their algorithmic approach to spindle cell melanocytic lesions and discuss each entity in turn, in order to (1) model a systematic approach to such lesions, and (2) provide familiarity with those melanocytic lesions that either typically or occasionally display a spindled cytomorphology.
\end{abstract}

\section{INTRODUCTION}

Melanocytic lesions of the skin can be a notorious challenge for the pathologist. ${ }^{1-5}$ This is due in part to the lack of consistent and reliable features differentiating benign from malignant melanocytic proliferations, but also to the great morphological variability that melanocytes can exhibit. 67 The former point is illustrated by the vast array of features that a pathologist must evaluate when confronted with a melanocytic entity, features that, when considered on their own, exhibit limited diagnostic utility. The general approach to diagnosing a melanocytic lesion is through a gestalt impression which incorporates: clinical parameters; architectural parameters including size, silhouette, pattern of growth and degree of maturation; cytological parameters including cytomorphology, extent of atypia and mitotic activity; and often ancillary studies as well. The morphological variability of melanocytic lesions is exhibited by both architectural and cytological variations. ${ }^{6} 8$ Particular difficulty arises when melanocytes express cytomorphological features that create uncertainty about the cell of origin, as may be seen with spindled melanocytic lesions. ${ }^{7} 9$ This difficulty is compounded when the architectural features most typical of melanocytic lesions are poorly developed or absent. This architectural and cytomorphological variability of melanocytes, in addition to the diagnostic challenges of differentiating benign from malignant lesions, accounts for the vast array of terms applied to melanocytic lesions-a list that can be intimidating. Numerous publications discuss selected challenges and pitfalls that may be encountered in the diagnosis of specific melanocytic entities. ${ }^{10-21}$ This review will focus specifically on spindle cell melanocytic lesions, with itemisation of those melanocytic entities that characteristically or occasionally show a spindled cytomorphology, with particular reference to diagnostically challenging situations and pitfalls. We also provide the algorithmic approach to these lesions that we use. The review is structured according to this approach. Part I deals with our algorithmic approach to spindle cell melanocytic lesions and includes their initial categorisation into compound naevoidal pattern lesions, Spitzoid lesions, intradermal proliferations and horizontally oriented lesions. $^{21 a}$ Part I further covers the compound naevoidal pattern lesions and the Spitzoid lesions. Part II continues with a discussion of intradermal melanocytic proliferations, horizontally oriented lesions and combined lesions.

Before embarking upon the hefty task of cataloguing a list of cutaneous spindle cell lesions, it is worthwhile attempting a definition for the widely used but fairly loosely defined 'spindle cell'. The term is one that is quite malleable to the needs of the pathologist and as such is rather freely used in cytological description of cellular morphology (figure 1). Perhaps, in its purest sense, spindling refers to cells with elongated fusiform nuclei. Such cells are best appreciated when they are present in a fascicular arrangement, imparting a streaming quality to the lesion. Fusiform spindled cells may be further qualified as: having rounded ends or being 'cigar-shaped' (eg, leiomyoma, many spindle cell melanomas); showing waviness or being 'commashaped' (eg, neuroma, neurofibroma, neuroidal naevus); or with tapered ends (eg, myofibroblasts, nodular fasciitis). Intermediate forms can also be seen and may appear blunted (eg, dermatofibroma, 
desmoplastic melanoma). Spindle cells may also vary in their thickness, appearing either plump (leiomyoma, melanoma) or thin (neurofibroma, fibromatosis, common blue naevi). Oval nuclei also impart a vague spindled quality, and many lesions with oval nuclei are classically listed as spindle cell lesions (eg, perineurioma, desmoplastic naevi, cellular blue naevi). The overall pattern of arrangement or other formations may offer further histogenetic clues (slit-like spaces in Kaposi sarcoma; storiform pattern in dermatofibrosarcoma protuberans; herringbone pattern in fibrosarcoma or malignant peripheral nerve sheath tumour (MPNST); palisading in neural lesions), as may other characteristic features (presence of nucleoli (eg, nodular fasciitis, melanoma), intranuclear inclusions (melanocytic lesions), subnuclear vacuoles (smooth muscle)). Spindle cells also encompass lesions with intermediate epithelioid and spindled morphologies, as may often be seen in histiocytic disorders such as Langerhans cell histiocytosis, dermatofibromas and atypical fibroxanthomas. Many melanocytic lesions offer further examples, such as frequent desmoplastic melanomas and Spitz naevi. Cellular-stromal interactions may further impart a spindling phenotype either by direct compressive effects or through chemical interaction. ${ }^{22-24}$ In general, interstitial infiltrating lesions may take on an oval or spindled morphology due to partial distortion as they infiltrate between collagen bundles. Given the standard option of describing a cell as either spindled or epithelioid, other cytomorphologies such as dendritic or stellate may thus also fall under the somewhat inappropriate label of spindled, including the common blue naevus, fibrous papules and dendritic cell tumours, particularly when the finer details may not be well appreciated on light microscopy. Finally, most epithelioid tumours also have spindle cell variants (and vice versa) (eg, epithelioid sarcoma, carcinoma). Clearly, the task of outlining spindle cell lesions becomes a laborious one when, by convention and practice, the term spindle cell: (1) encompasses a range of differing cytomorphologies; (2) may arise by nature of the histogenetic origin of the lesion, the nature of the lesional cells or the effects of the surrounding stroma; or (3) may be applied in intermediate, admixed or even inappropriate settings to satisfy convention or simplicity. Nevertheless, in this article, we try to consider all the possible applications of the term spindle cell to melanocytic lesions, but also try to put the term in appropriate context with respect to finer cytomorphological descriptions that offer diagnostic utility. After all, even though a neuroidal naevus, a cellular blue naevus and a pigmented spindle cell naevus of Reed are all spindle cell melanocytic lesions, they can still be distinguished from each other on the basis of cytomorphology alone.
Figure 1 Examples from the morphological spectrum of 'spindle cells' (all images: H\&E; 600×). (A) Wavy or 'comma-shaped' (neuroidal) spindle cells from the tactoid bodies of a neuroidal naevus (56-year-old woman; shoulder). (B) Slender bipolar spindle cells from a common blue naevus. Ovalshaped melanocytes can also be seen towards the upper left (63-year-old woman; shoulder). (C) Blunted oval spindle cells from a satellitic nodule of a plaque-type cellular blue naevus (50year-old woman; abdomen). (D) Plump 'histiocytoid' spindle cells from a desmoplastic melanoma (54-year-old man; forehead). Spitzoid lesions also typically show a spindle cell component that varies from histiocytoid to fusiform with additional characteristic Spitzoid features (figure 5B). (E) Fusiform spindle cells from a spindle cell melanoma (79-year-old man; lower back). Prominent nucleoli, high-grade nuclear atypia, mitotic activity and clear cytoplasm are noted as additional features in this case. (F) Cytological preparation of a metastatic spindle cell melanoma. Elongated fusiform cells with high-grade cytological features are noted in this aspirate (78-year-old man; subcutaneous submandibular mass). (Image courtesy of Dr William Geddie).
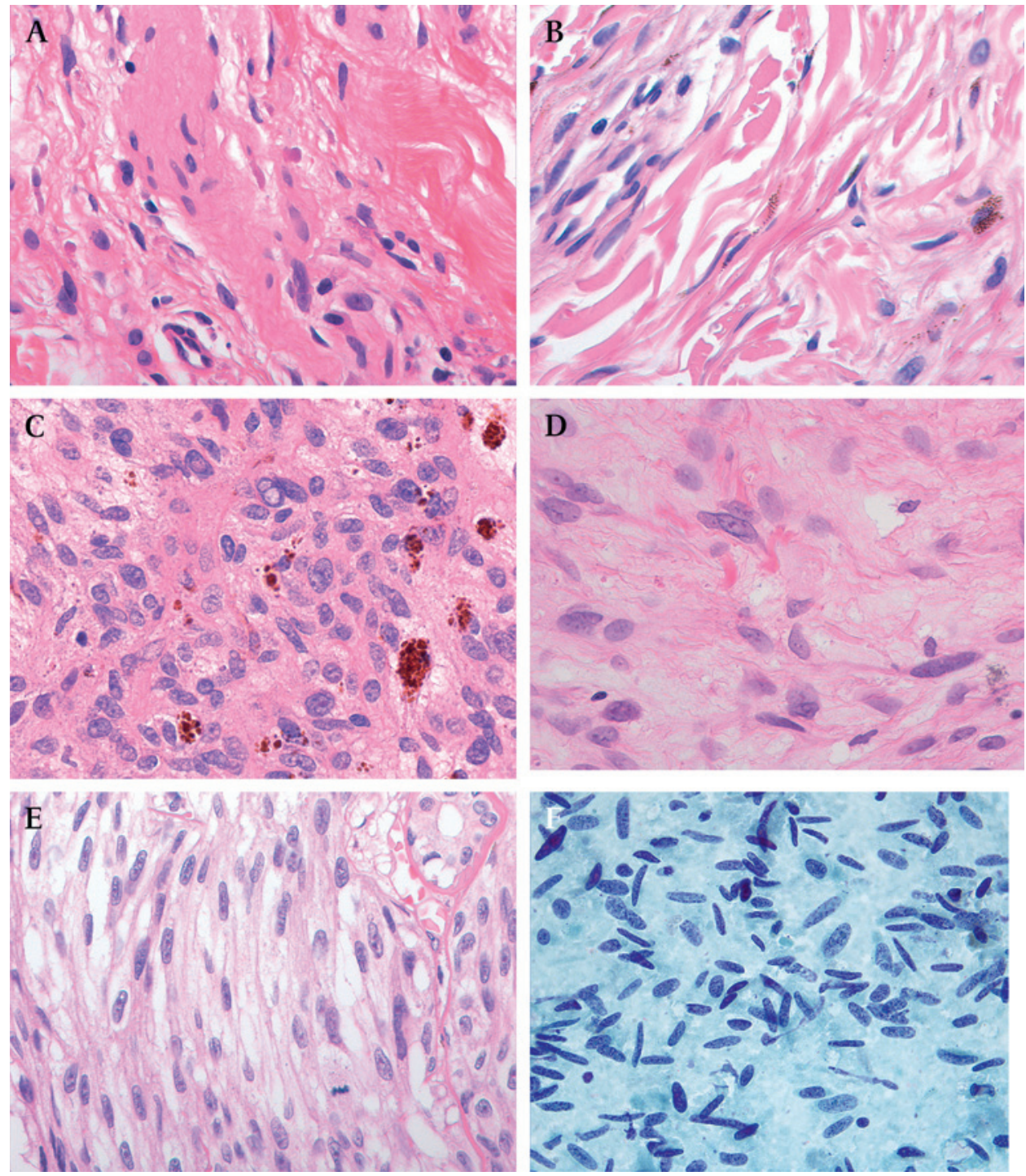


\section{ALGORITHMIC APPROACH TO MELANOCYTIC SPINDLE CELL TUMOURS (FIGURE 2)}

Establishing the histogenetic origin of a cutaneous spindle cell lesion: histopathological assessment, ancillary testing and clinical correlation

When first confronted with a spindle cell tumour of the skin, the first step is to classify the histogenetic origin of the lesional cells before proceeding with further diagnostic categorisation. Although for many cell types, a spindled morphology often equates with a lack of differentiation or metaplastic differentiation (eg, epithelia), for other cell types, spindling represents the appropriate differentiated morphology of the cells (eg, peripheral nerve sheath, smooth muscle, fibroblasts/myofibroblasts). Evaluating the histomorphological features of spindled tumours is an essential step in establishing the histogenetic origin of many spindled lesions. Although non-melanocytic spindled lesions are not the focus of this review, an approach to cutaneous spindle cell melanocytic lesions cannot proceed without consideration of the potential non-melanocytic mimics that often arise in the differential diagnosis; therefore we have listed some useful clinical, histological and immunohistochemical features of nonmelanocytic spindle cell lesions in table 1 . Suffice it to say that for certain non-melanocytic spindle cell tumours, histomorphology alone is generally sufficient for confident diagnosis, whereas, in others, ancillary methods (usually immunohistochemistry) are required in the diagnostic work-up. The reader is also referred to other excellent publications for consideration of non-melanocytic cutaneous spindle cell lesions. ${ }^{25-32}$ For melanocytes, spindling is a common and, even occasionally, a definitive feature in certain types of melanocytic lesions (eg, blue naevi, Spitz naevi, melanoma). Spindling in melanocytes does not necessarily reflect a lack of differentiation, and, in fact, the epithelioid morphology of naevomelanocytes seen in most common melanocytic naevi reflects a deviation from the functional dendritic morphology of intraepidermal melanocytes. ${ }^{21} 33$ Even nesting, the characteristic organisational pattern of melanocytic lesions, represents a deviation from the isolated and territorial behaviour of functional melanocytes. Furthermore, type C ('Schwannian') melanocytes represent a maturation phenomenon that may occasionally be seen in aged melanocytic naevi ('neuroidal naevi', 'naevi with neurotisation'). ${ }^{34}$ Alternatively, high-grade melanomas often take on a spindled morphology, reflecting a metaplastic or dedifferentiation phenomenon. ${ }^{6} 9313536$ Nonetheless, in most cases of spindle cell melanocytic lesions, melanocytic differentiation may be determined/inferred through evaluation of the histomorphological features of the lesion (box 1), whereas in others further ancillary testing is required (table 2). ${ }^{6} 212637-54$

Assessing the biological potential of melanocytic spindle cell tumours

Having optimally established the histogenetic origin of a lesion through clinical parameters and histomorphology with or without ancillary studies, the next step in the algorithmic

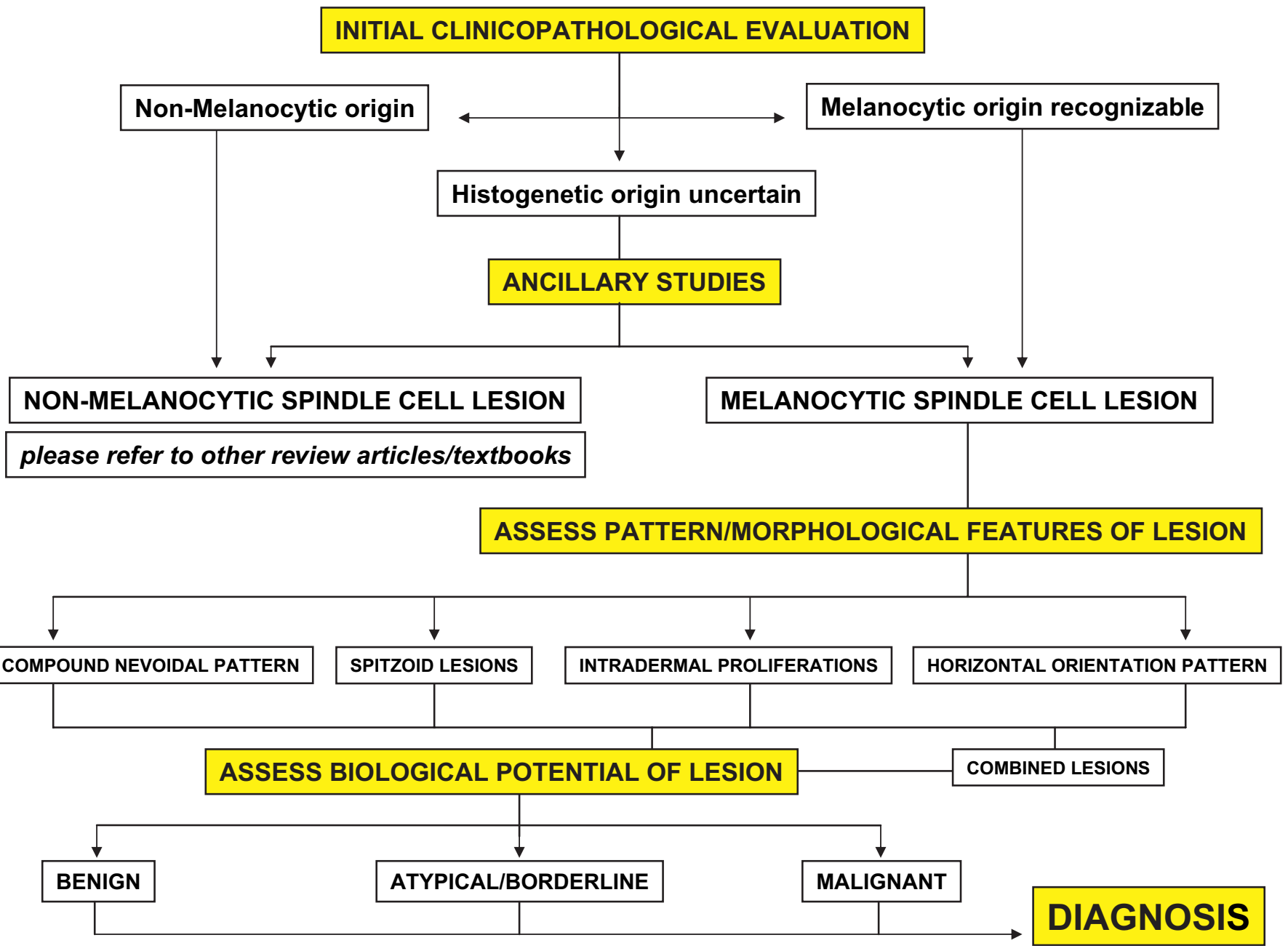

Figure 2 Algorithmic approach to a cutaneous spindle cell lesion. 


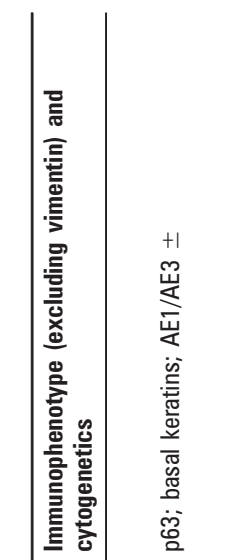

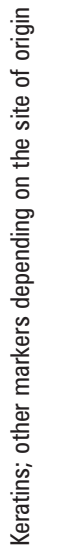
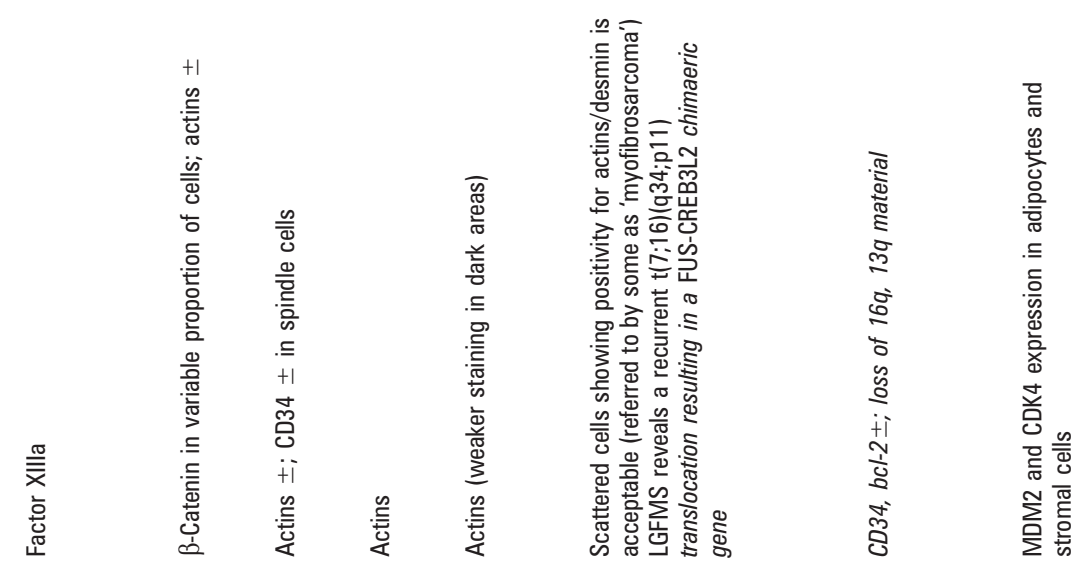

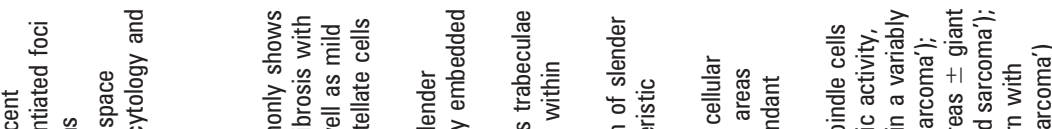

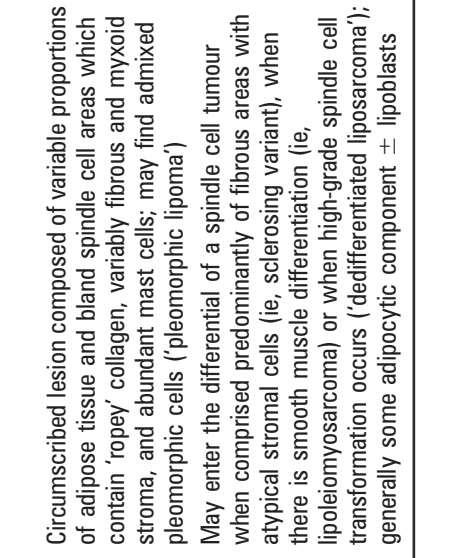

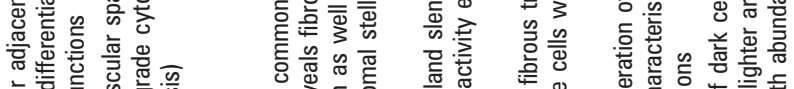

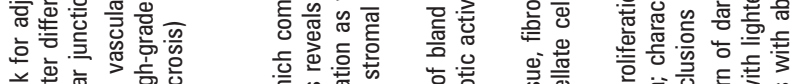

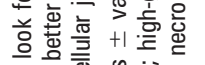

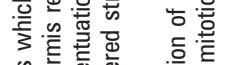

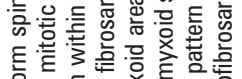

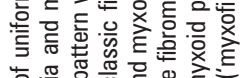

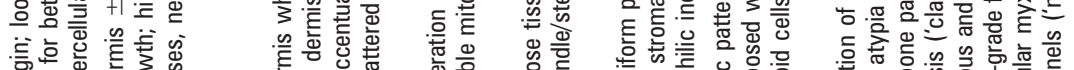

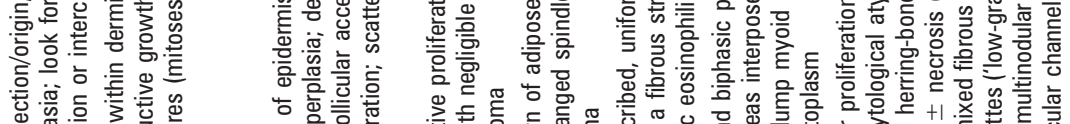

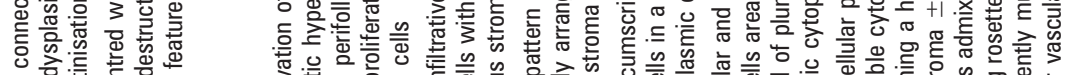

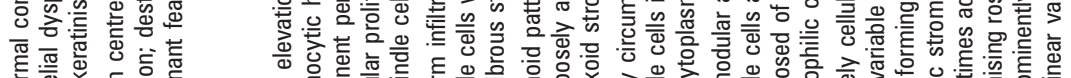

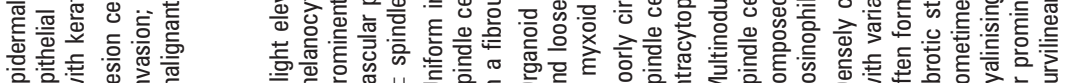

옹

곤

○
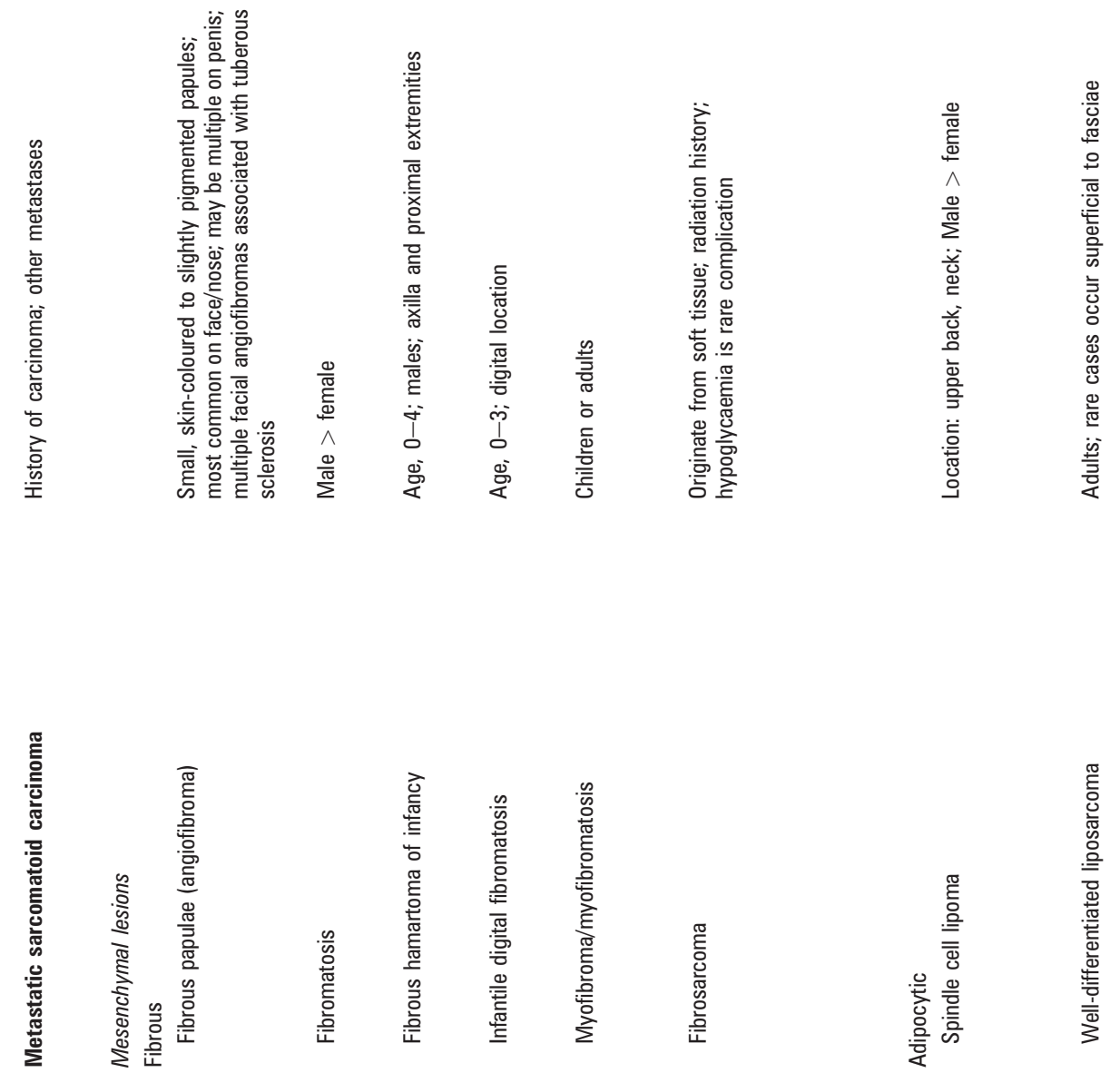


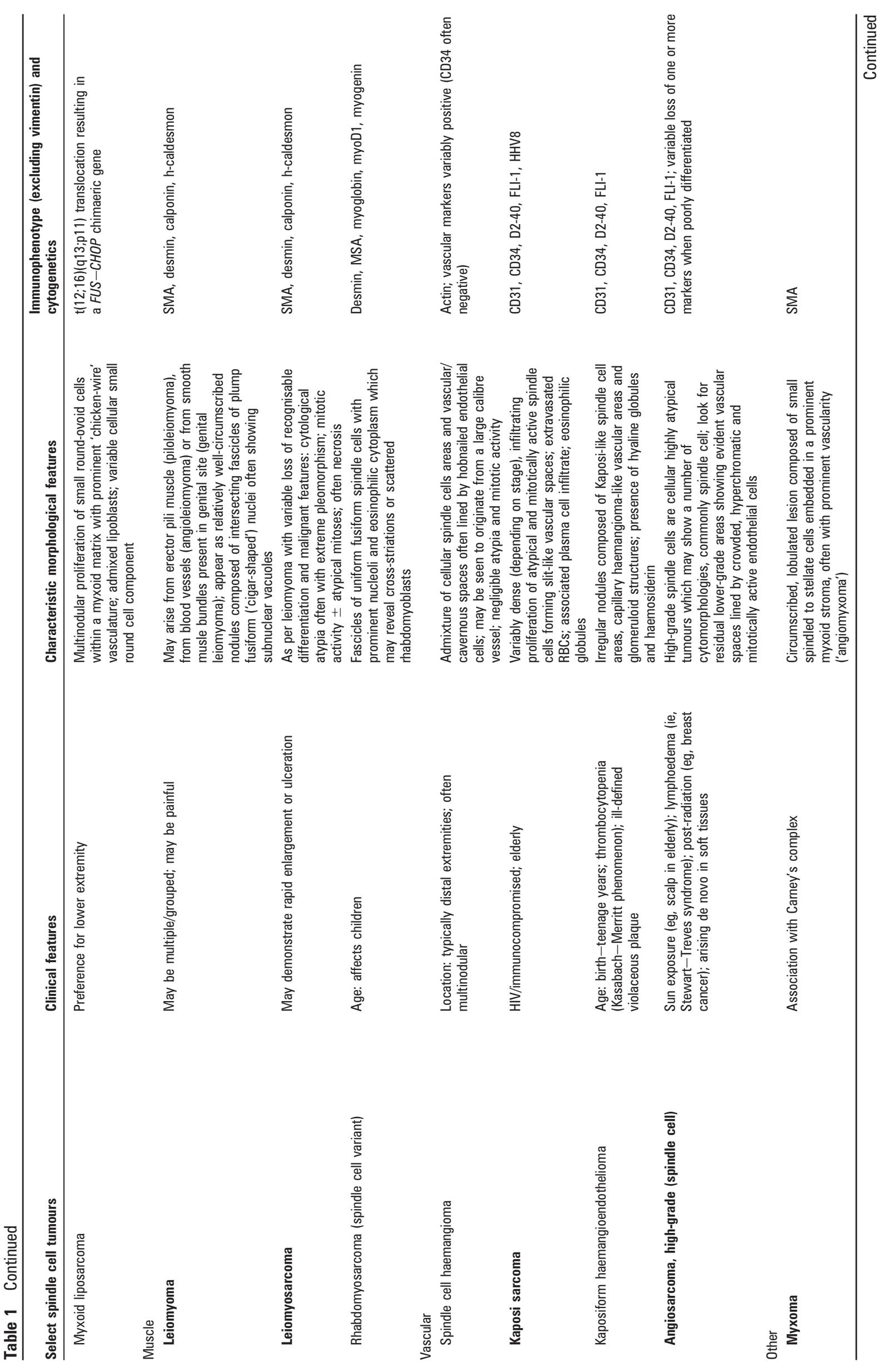

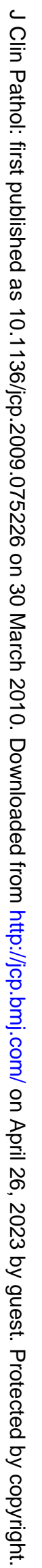




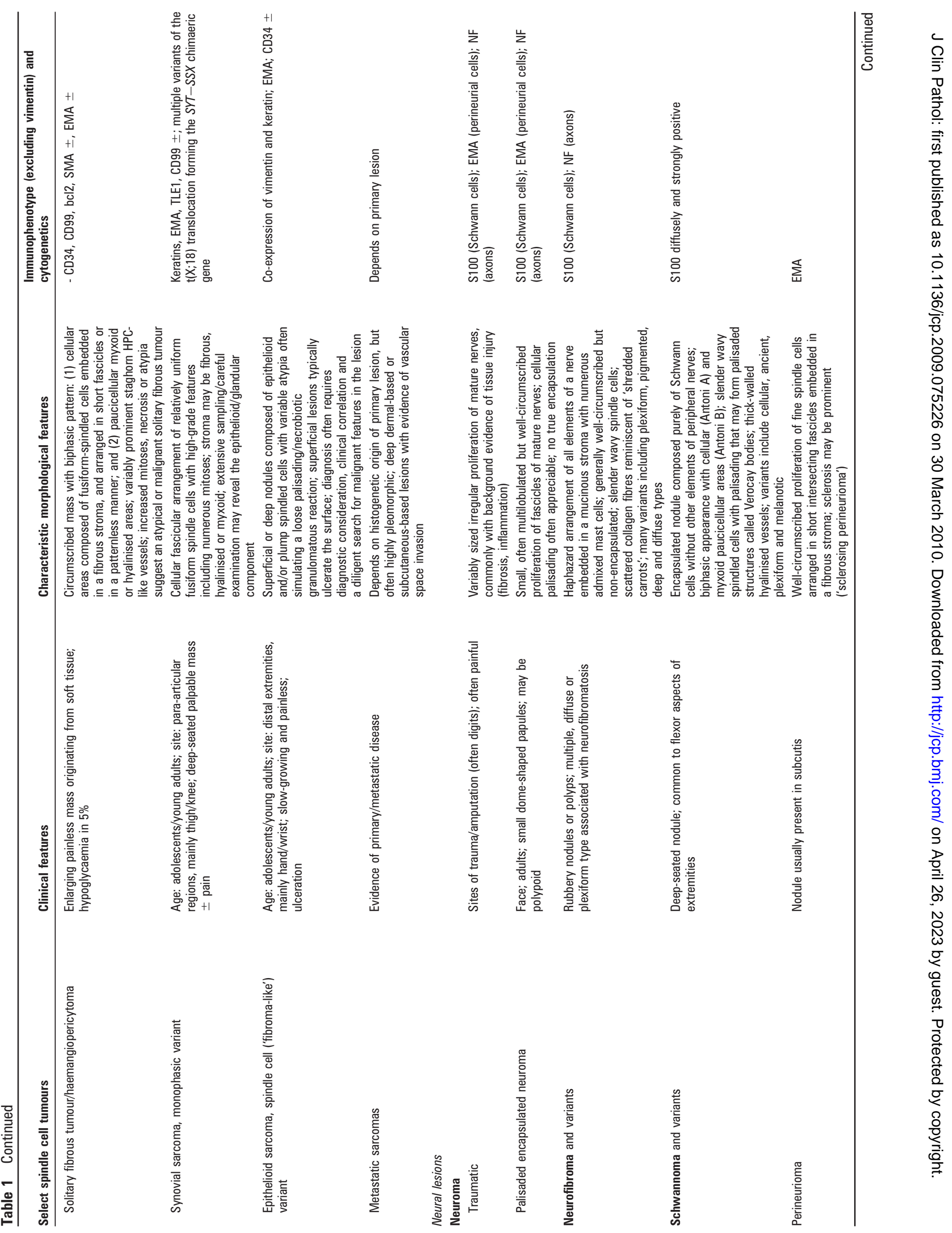




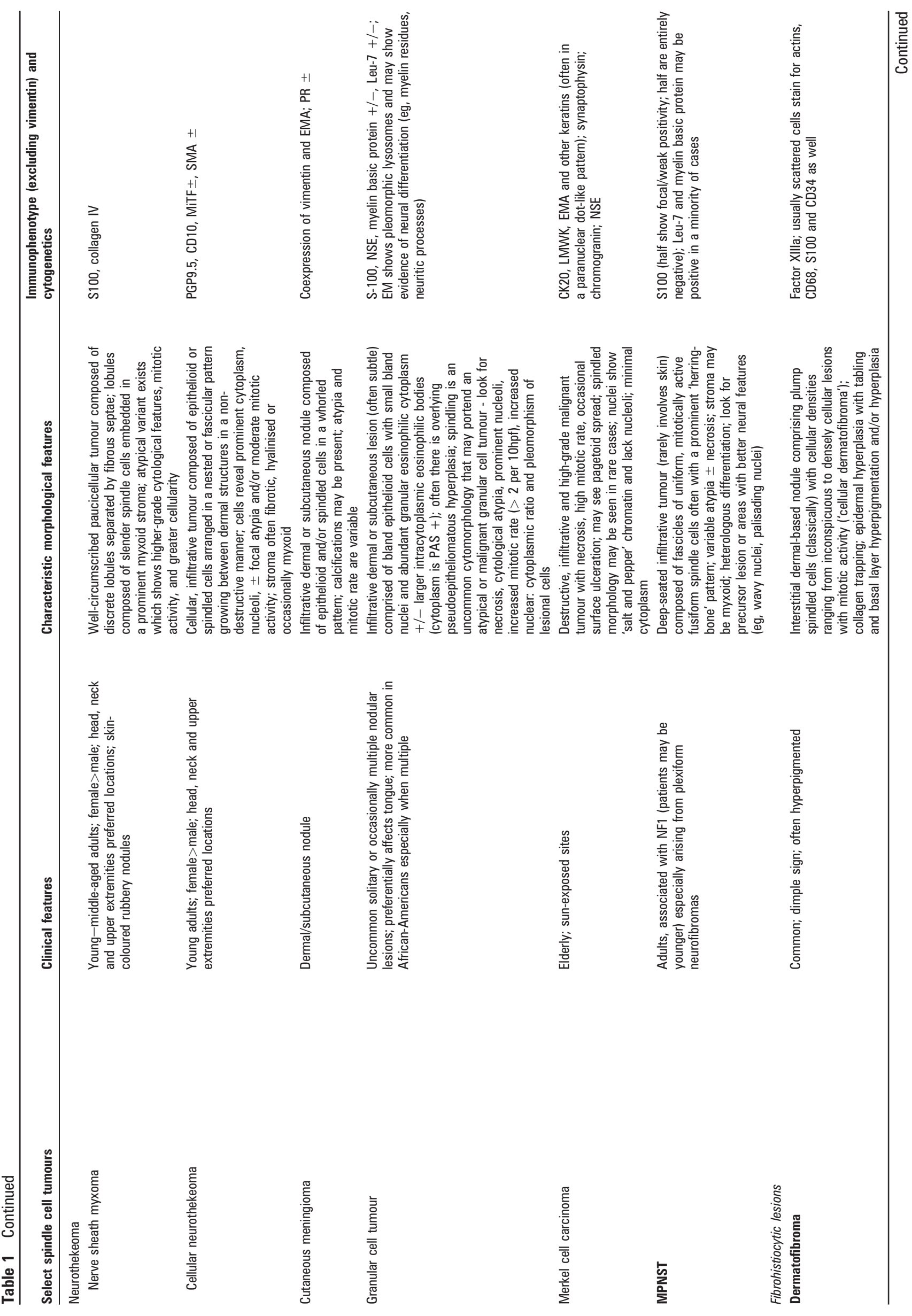




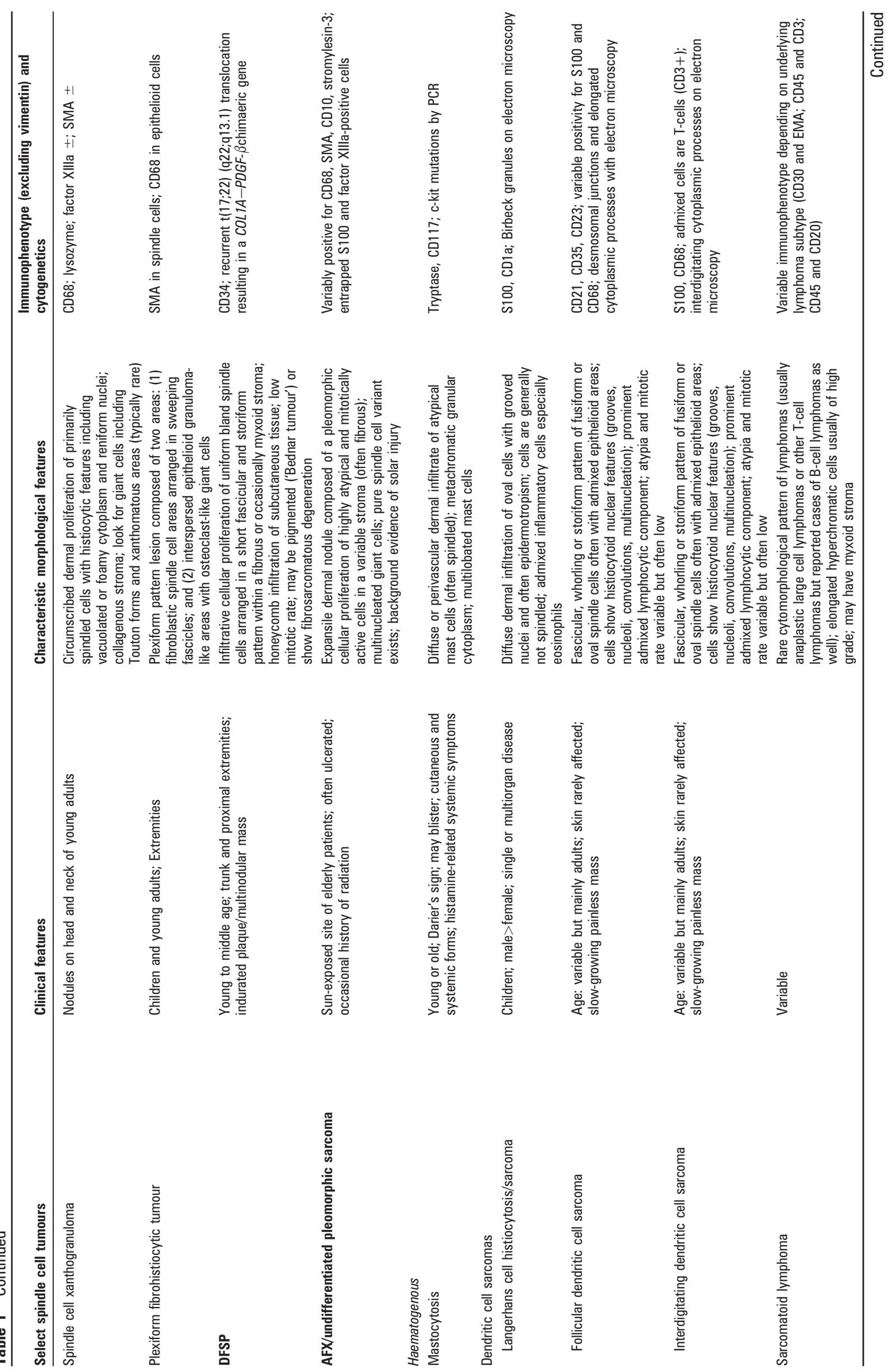

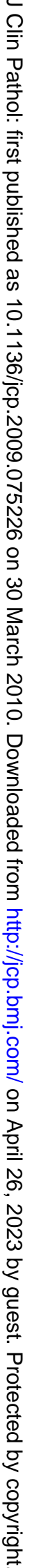




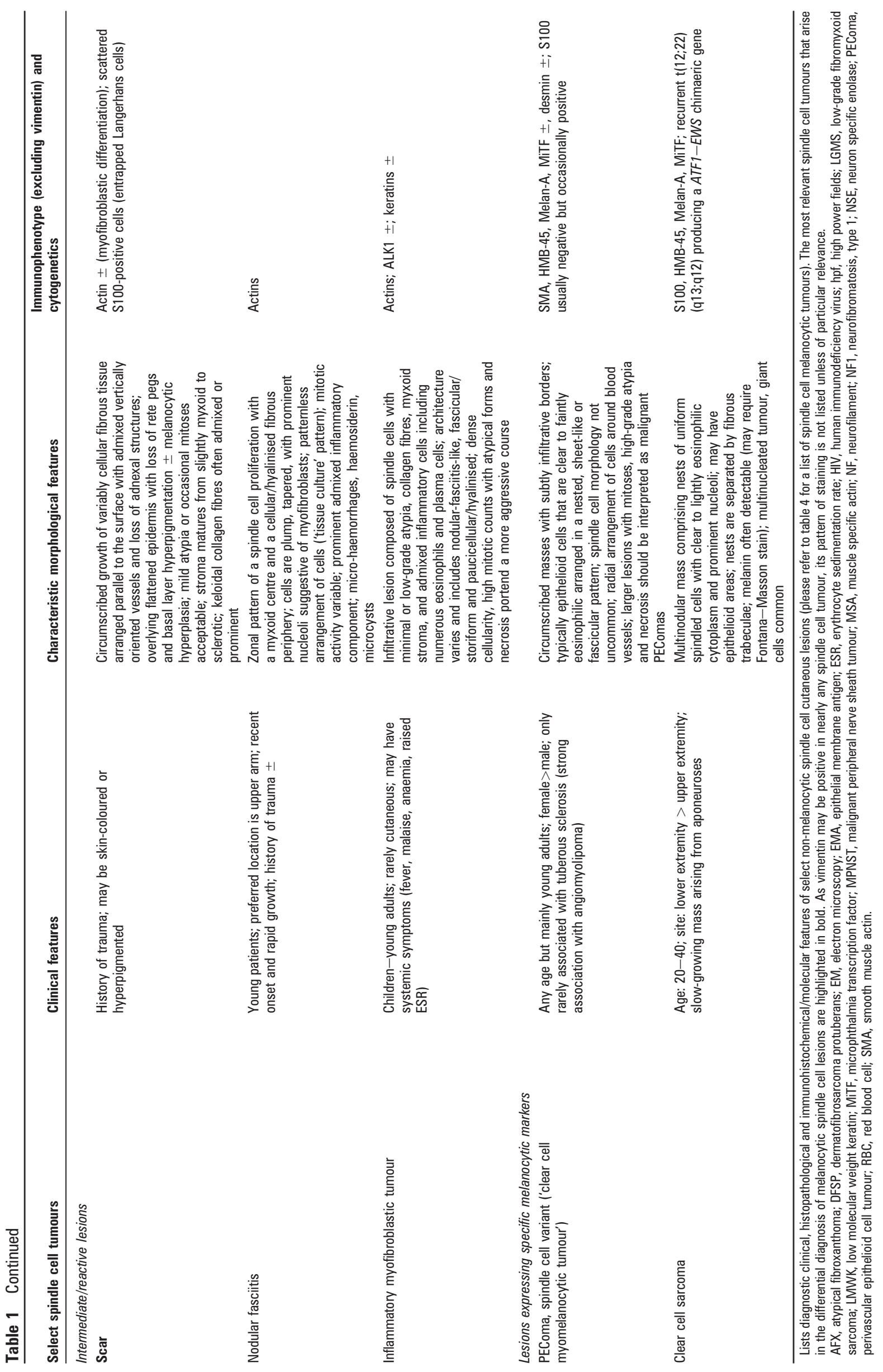


Box 1 Histomorphological features suggestive of melanocytic differentiation in a spindle cell lesion

Cytomorphological features suggestive of melanocytic differentiation

- Melanin pigmentation

- consider other pigments: haemosiderin, exogenous pigment, lipofuscin

- consider melanin production in non-melanocytic lesions

- consider melanin incontinence in non-melanocytic lesions

- Intranuclear cytoplasmic inclusions

- Multinucleation

- Nucleoli (typically prominent in melanoma)

- Cytoplasm variable in terms of quantity and character

Architectural features suggestive of melanocytic differentiation

- Epidermal component

Junctional location

Nested pattern

Lentiginous pattern

Pagetoid pattern

- Dermal component

Nested pattern

Congenital pattern (including growth along adnexal and neurovascular structures; herniation of melanocytic nests into dilated lymphovascular structures)

Other patterns may also be seen (diffuse, trabecular, pseudovascular)

Evidence of dermal maturation

- Stromal response may be evident

Lymphocytic infiltrate/reaction

Dermal fibrosis

Presence of melanophages

Other regressive features (irregular scattering of lesional cells, vascular proliferation)

Other features consistent with a melanocytic lesion

- Look for background/admixed clear-cut melanocytic lesion

- Presence of solar elastosis (for certain entities)

- Macroscopic 'gross' features (pigmentation, ABCD criteria)

- Lack of features to suggest non-melanocytic origin (table 1)

- Histochemical staining

Fontana-Masson or Schmorl staining for melanin pigment Melanin bleach

DOPA reaction to demonstrate tyrosinase activity

- Immunohistochemical phenotype (table 2)

- Ultrastructural demonstration of melanosomes/pre-melanosomes

approach to a spindle cell melanocytic lesion is to assess the lesion's biological/malignant potential. Classic pathological tenets teach us that such potential generally correlates very closely with cytological atypia/anaplasia (ie, cytological features) and invasive/destructive growth (ie, architectural features). Unfortunately, in the realm of melanocytic lesions, this approach may be misleading in a number of settings. For instance, Spitz naevi and naevoid melanomas are two examples where the degree of cytological atypia fails to reflect the true biological potential of the lesion. Spitz naevi, deep penetrating naevi and cellular blue naevi are examples of benign spindle cell melanocytic lesions that typically show infiltrative patterns that disguise their benign nature. Desmoplastic melanomas on the other hand are infiltrative lesions with full malignant potential. Furthermore, invasion is a difficult concept to appreciate in melanocytic lesions because precursor melanocytic cells/melanoblasts migrate from the neural crest through the dermis to reach their ultimate 'supposed' epidermal location (as well as other sites of normal melanocyte migration). ${ }^{21} 5556$ Hamartomatous malmigration may occur, resulting in a variety of dermal or combined lesions. Furthermore, naevic aggregates that have successfully completed upward migration through the dermis into the epidermis still undergo a normal maturation pattern of 'falling off' from their initial intraepidermal location with descent into the dermis. Thus there are no reliable tissue barriers available to evaluate definitive invasive growth. Rather, through the determination of malignant cytological and architectural features, a melanoma is considered 'invasive' (or perhaps more accurately, capable of local invasive behaviour and distant spread), once it is present within the dermis and thus potentially accessible to nerves, lymphatics and other vascular spaces. This, of course, presumes a junctional origin for melanoma; however, rare examples of completely intradermal melanomas are known (eg, malignant blue naevus, malignancy arising within the dermal component of a congenital naevus, primary dermal melanoma). Thus, in many respects, determination of the biological/malignant potential of a melanocytic lesion must rely on other evaluated features.

Owing to the high clinical detectability of cutaneous melanocytic lesions, their relative commonality, and their general ease of excision, there has accumulated a general wealth of experience that has permitted the correlation of histopathological features with biological behaviour. Unfortunately, no single feature (except in extreme cases) allows reliable discrimination of benignancy from malignancy. Rather, a gestalt impression is formed by weighing the relative value of numerous clinical and histopathological features with or without immunohistochemical features in order to predict the biological behaviour (and thus achieve a diagnosis) of a given lesion. It is this generalised understanding of the correlation between a host of histopathological features and biological outcomes that outlines the standard approach to melanocytic lesions (table 3). However, owing to the significant morphological variability of melanocytic lesions, there exist numerous examples of lesions that violate these generalised rules (eg, deep expansile cellular nodules in cellular blue naevi; cytological atypia and pagetoid activity in Spitz naevi), and so, phenotypic categories are created that permit a more precise assessment of the biological potential associated with each histological feature. It is with this objective that an initial pattern approach offers clinical value.

\section{Architectural patterns of melanocytic spindle cell lesions}

Recognising that a dogmatic cytomorphological and generalised architectural approach applied universally to spindle cell melanocytic lesions may be misleading, an architectural patterns approach may be used to categorise melanocytic lesions into specific recognised patterns for which generalised rules may be applied in a more reliable manner in order to qualitatively assess the biological potential of a given lesion. Four general architectural families can be defined (figure 3):

A. Compound naevoidal pattern

B. Spitzoid lesions

C. Intradermal proliferations

D. Horizontal orientation pattern

Assessment of biological potential follows somewhat differently for lesions in each pattern category. Ultimately it is the clinicopathological experience with different lesions that guides thresholds for diagnostic terminology. Each category will be discussed further in the following section with a focus on highlighting the features that allow most precise assessment of biological potential. Table 3 lists the features that should be 
evaluated when a melanocytic lesion is encountered and states in a general way the impact that each has upon the estimated biological potential of the lesion. Of course, consideration must be given to the lesion being dealt with before applying relative weight to the findings (eg, pagetoid spread is of significant concern in a Clark's naevus but a well-established finding in benign acral naevi; perineural location of lesional cells may be seen in blue naevi but is otherwise generally indicative of malignancy).

\section{Reaching a diagnosis}

Outside of a few well-recognised melanocytic entities, the pathological diagnosis of melanocytic lesions is daunting for many. This is, in part, due to the great array of diagnostic terms available. The long list of existing melanocytic lesions reflects two aspects of melanocyte pathobiology:

1. The cytomorphological and architectural diversity of melanocytic lesions

2. The difficulty in recognising universally reliable histomorphological features to accurately reflect the biological potential of melanocytic lesions.

The first point reflects the traditional morphologist's view, in which diagnostic entities are defined by their histomorphological appearance (eg, neuroidal naevus, desmoplastic naevus, pigmented spindle cell naevus). The second point reflects the utilitarian need to communicate in a diagnostic term the clinical potential of a lesion (eg, naevi of special sites, atypical Spitz tumour, melanoma). Despite this great range of lesional names in melanocytic pathology, it should be remembered that the ultimate aim of diagnosis is to guide clinical management of a lesion, and so should reflect the biological potential of the lesion. Ultimately, this means that, despite the terminology used, a lesion fundamentally falls into one of three categories:

1. Benign-essentially no risk of aggressive/malignant biological potential (eg, compound naevus)

2. Atypical/borderline

a. Atypical lesions-lesions that are overall consistent with a benign lesion but which display unsettling atypical features that may portend a more aggressive course (eg, atypical blue naevus, common or cellular)

b. Lesions of uncertain biological potential-lesions that generally behave in a benign manner but with exceptions common enough to warrant conservative management (eg, cutaneous neurocristic hamartoma), or rare lesions for which the natural history is not confidently known (eg, plaque-type cellular blue naevi with satellitic nodules)

c. Borderline lesions-lesions with pathological features that overlap with those of malignant entities to the point that assurance that the lesion is not in fact its malignant mimic cannot be reliably made (eg, Clark's naevus with high-grade atypia; junctional Clark's naevus bordering on melanoma in situ)

3. Malignant-malignant biological behaviour is predicted (or a significant risk to progress to such for in situ lesions) (eg, nodular melanoma)

In making diagnoses, one should thus concern oneself with the application of diagnostic terminology that relays precise transmission of the lesion's histogenetic origin and its risk of aggressive/malignant biological behaviour, thus facilitating appropriate clinical management decisions. Often melanocytic lesions may not fall neatly into any predefined category, and a descriptive diagnosis or qualifying statement may best accomplish this task. On occasion, we do find it acceptable to use the term 'melanocytic lesion of undetermined malignant potential' (MELTUMP) for lesions that exhibit features that raise concern about their biological potential, and also fail to satisfactorily show clinical, architectural and cytomorphological features to define them as an established entity. Such a diagnosis should not be ashamedly felt as a failing of the pathologist's diagnostic ability, but rather the final deduction that the biological potential of the lesion in question simply cannot be accurately predicted on the basis of clinical, histological and cytological data with or without other ancillary information, despite a diligent attempt to do so. In addition, there should be no better diagnostic term to reflect the histology of the lesion in a way that still communicates its uncertain biological potential (eg, atypical Spitz naevus, atypical cellular blue naevus, Clark's naevus with high-grade features). On such occasions, a comment is warranted to more precisely describe the pathological difficulty, estimate the biological risk of the lesion, and provide management recommendations. Nevertheless, optimal communication is best achieved when terminology is well defined and strongly established, and so, when possible, the most established and simplest diagnostic terms should be used. Thus, whenever possible, we do avoid terms, such as MELTUMP, that do not effectively communicate a lesion's biological potential or its architectural pattern. Towards this end, we begin our discussion of the most established and useful diagnostic entities within the spindle cell melanocytic spectrum (table 4) with a focus on the diagnostic features and potential pitfalls.

\section{SPINDLE CELL MELANOCYTIC LESIONS Compound naevoidal pattern lesions (figure 4)}

The first architectural pattern is the "compound naevoidal pattern', which exhibits underlying architectural features reminiscent of an ordinary naevocellular naevus, prototypically with both a junctional and an intradermal component (see box 2 for notable pitfalls). This is the most common melanocytic pattern encountered. Naevoidal pattern lesions are generally circumscribed and symmetric compound melanocytic lesions. They tend to present as macules or papules, but may also be domeshaped, papillomatous or occasionally polypoid. Benign naevoidal lesions show organised growth that is often nested and lacking confluence or irregularity in pattern. Junctional shouldering should not be prominent. With age, compound naevoidal lesions tend to mature via descent into the dermis, and some lesions may thus lack an appreciable junctional component. Such lesions still maintain the remaining naevoidal features, and so are still considered consistent with an overall 'naevoidal' pattern, albeit intradermal rather than compound Malignant lesions may preserve a naevoidal appearance, but generally show superimposed features of concern to varying degrees (eg, large size, dense confluent growth, deep expansile growth, pagetoid spread, dermal mitoses). Papillomatous or verruciform epidermal changes occasionally accompany both benign and malignant 'naevoidal' lesions. Cytomorphology may

Box 2 Notable challenges/pitfalls in the evaluation of naevoidal pattern spindle cell melanocytic lesions

Atypical spindle cell proliferation in a congenital naevus versus spindle cell melanoma arising within a congenital naevus. Naevi of special sites exhibiting pseudomelanomatous features versus melanoma arising in special sites.

Diagnosis of naevoid melanoma with spindle cell morphology. Spindle cell melanoma versus other spindle cell lesions. 


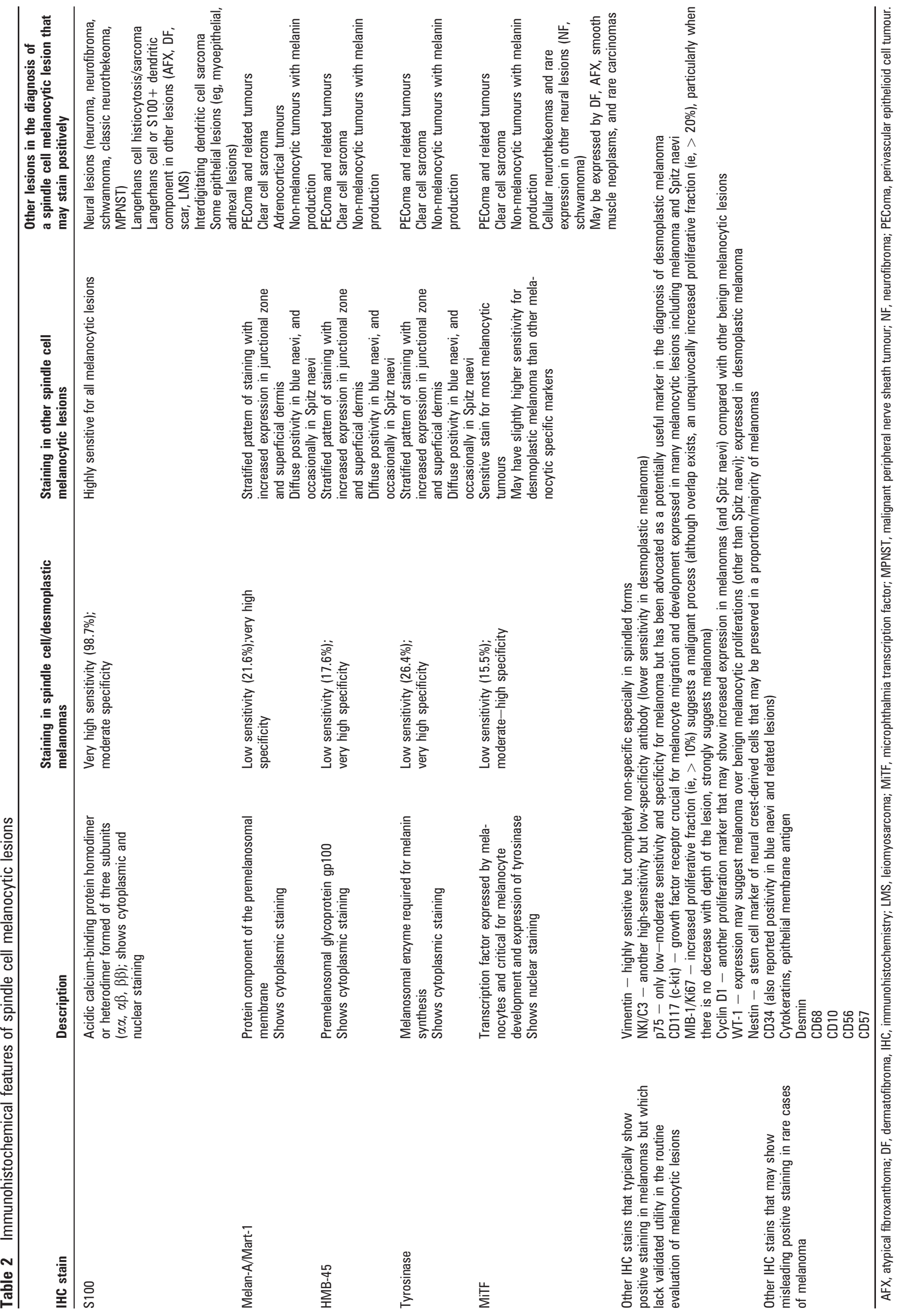

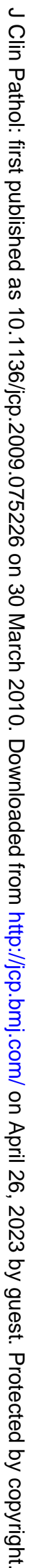


Table 3 General approach to melanocytic lesions: evaluation of clinical and pathological features

\begin{tabular}{|c|c|c|}
\hline Histopathological feature & Favours benign & Favours malignant \\
\hline \multicolumn{3}{|l|}{ Clinical } \\
\hline Age & Children/young adult ( $<30$ years) & Adults/elderly ( $\geq 30$ years) \\
\hline Gender/location & $\mathrm{M}=\mathrm{F}$; any location & $\mathrm{M}$, trunk; $\mathrm{F}$, trunk/lower extremities \\
\hline Borders/circumscription & Irregular & Regular \\
\hline Size/diameter & $<10 \mathrm{~mm}$ & $>10 \mathrm{~mm}$ \\
\hline Symmetry & Symmetrical & Asymmetrical \\
\hline \multicolumn{3}{|l|}{ Architectural } \\
\hline Size & $<10 \mathrm{~mm}$ & $>10 \mathrm{~mm}$ \\
\hline Symmetry & Symmetrical & Asymmetrical \\
\hline Circumscription & Well circumscribed & Poor circumscription \\
\hline Regularity† & Regular & Irregular \\
\hline Density of growth & Uniform, non-dense & Dense, sheet-like or confluent growth \\
\hline Nuclear size & Small (less than keratinocyte) & Large (larger than keratinocyte) \\
\hline Nuclear/cytoplasmic ratio & Low & High \\
\hline Chromasia & Hypo/normochromatic & Hyperchromatic \\
\hline Pleomorphism & Absent & Present \\
\hline Nuclear membranes§ & Regular: thin and uniform & $\begin{array}{l}\text { Irregular: non-uniform thickenings, } \\
\text { abnormal nuclear shapes }\end{array}$ \\
\hline Nucleoli & Absent-variable/small & Present-macronucleoli, multiple nucleoli \\
\hline Chromatin & Fine/dispersed & Coarse \\
\hline Cellular cohesion & Cohesive & Dyscohesive \\
\hline Pigmentation & Coarse melanin granules & Fine dusty melanin, amelanotic \\
\hline Cytological maturation $\ddagger$ & Present & Absent $\uparrow$ \\
\hline \multicolumn{3}{|l|}{ Stromal } \\
\hline $\begin{array}{l}\text { Immunophenotypic maturation (HMB- } \\
45, \text { proliferative index) } \neq\end{array}$ & $\begin{array}{l}\text { Stratified staining pattern with loss of } \\
\text { dermal expression with descent }\end{array}$ & Diffuse positivity \\
\hline \multicolumn{3}{|l|}{ Other } \\
\hline Mitotic activity & Negligible; none in deep dermis & $\begin{array}{l}\text { Increased numbers, deep dermal forms, } \\
\text { clustering atypical forms, mitoses in } \\
\text { pagetoid cells }\end{array}$ \\
\hline Perineural invasion & Absent & May be present \\
\hline Angiolymphatic invasion & Absent & May be present \\
\hline Necrosis & Absent & May be present \\
\hline
\end{tabular}

*Benign exceptions exist-please see text.

†Regularity of growth refers to a nested (or occasionally diffuse) pattern that shows uniformity in size and shape of nests, and which does not reveal destructive growth or large expansile nodules.

¥Maturation may be evident in three ways: architectural—diminishment of nesting pattern with decrease in nest size; cytological—decrease in size of melanocytes with loss of cytoplasm and nucleoli; immunophenotypic-loss of activated melanocytic markers (HMB-45, decreased proliferative index).

§Intranuclear cytoplasmic inclusions are a common feature of melanocytes both benign and malignant and offer no discriminating value in terms of biological potential; however, other nuclear membrane irregularities are suggestive of an atypical/malignant lesion (eg, nuclear membrane thickenings, nuclear snouts/indentations/grooves).

TDo not mistake a residual dermal naevic component as evidence of maturation.

**Plasma cells may accompany foci of scarring or concurrent inflammatory conditions.

$\dagger †$ Regressive features include: fibrosis, mononuclear inflammatory infiltrate, vascular proliferation, presence of melanophages, and a scattered distribution of any remaining dermal component (ie, in partial regression).

$\neq \ddagger$ See also table 2.

vary from bland and quiescent to overtly malignant. Distinguishing benign from malignant lesions exhibiting this pattern is generally not challenging, with the notable exception of naevoid melanoma, which is often a challenging diagnosis that may be revealed when there are subtle or pronounced deviations from the standard naevoidal architecture or bland cytomorphology in an otherwise naevoidal pattern lesion. In certain cases, the diagnosis may only be made in retrospect following clinically evident malignant behaviour of a lesion. The spindle cell melanocytic lesions characterised by a compound naevoidal pattern are discussed in turn as follows:

1. Neuroidal naevus/melanocytic naevus with neurotisation

2. Congenital naevus with spindle cell component

3. Naevi of special sites 

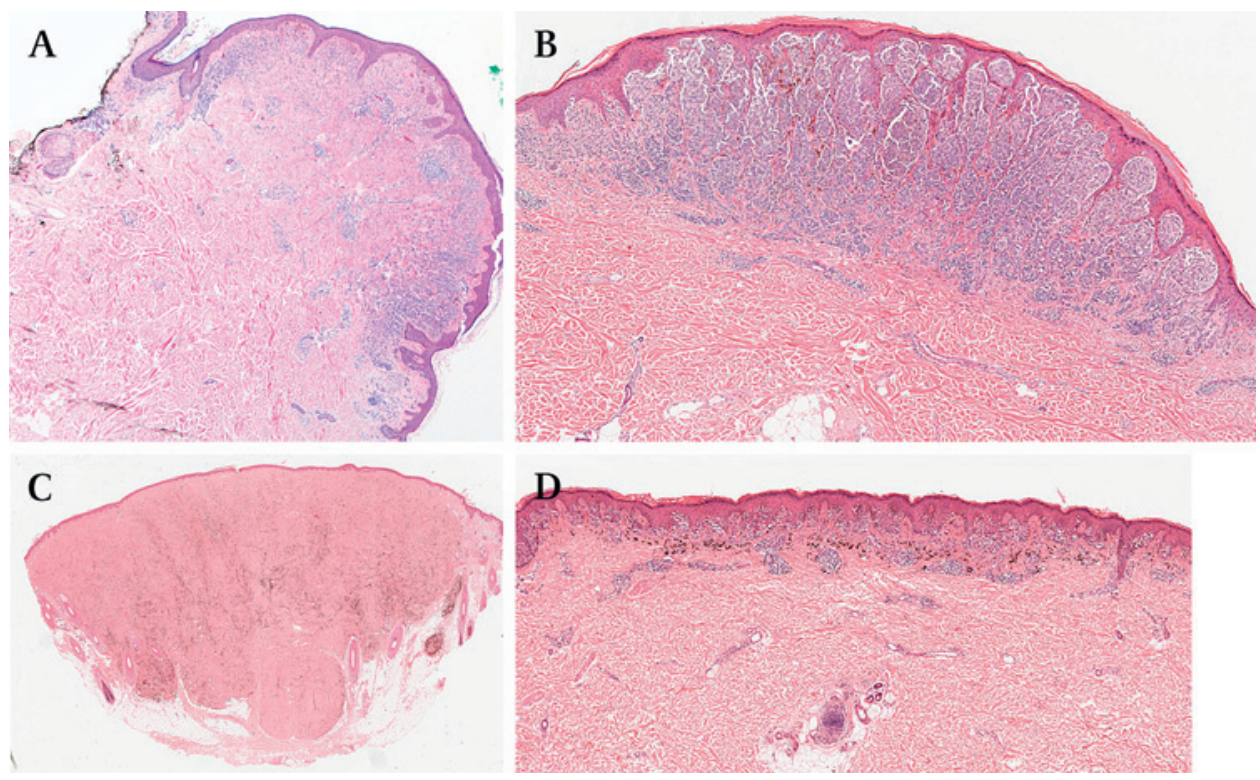

Figure 3 Architectural patterns of spindle cell melanocytic lesions. (A) Compound naevoidal pattern (H\&E; 30×). Observe the well-circumscribed and symmetrical compound architecture of this compound naevus with partial dermal desmoplasia (49-year-old man; abdomen). The lesion is domeshaped and shows prominent nesting and an organised appearance. Oval-type spindle melanocytes can be seen in the desmoplastic areas on higher power. The nature of the lesion is otherwise readily apparent from the surrounding type A naevocellular melanocytes. (B) Spitzoid pattern (H\&E; $50 \times$ ). Spitzoid lesions are characterised by both architectural features and cytological features (table 6 and figure 6). This atypical compound Spitz tumour (50-year-old woman; upper back) shows the typical Spitzoid silhouette including small size, sharp circumscription and prominent symmetry. Epidermal hyperplasia and retraction artifacts around large, vertically oriented junctional nests are also readily apparent. Partial dermal maturation may also be seen at low power. Concern regarding this lesion was raised because of its prominent epithelioid cell component and increased mitotic activity, including mitoses at the deep front of the lesion. (C) Intradermal pattern (H\&E; 10X). This common blue naevus (67-year-old woman; posterior neck) shows an infiltrative melanocytic lesion confined to the dermis with prominent melanophages. The background dermis is fibrotic. The lesion is rather prominent, large and deeply infiltrative with a bulging margin, which is generally more in keeping with a cellular blue naevus; however, cellular areas were not noted to warrant a diagnosis of cellular blue naevus. This represents one typical pattern of intradermal melanocytic proliferations. A second pattern is the presence of nodular intradermal aggregates of spindled melanocytes in confluent nests or fascicles, as may be seen in metastatic melanoma or melanocytoma. (D) Horizontally oriented pattern (H\&E; 20X). Prominent junctional/radial growth is characteristic of a number of melanocytic lesions, and such lesions may show spindle cell morphology, as seen in this compound Clark's naevus (33-year-old man; thigh). The junctional nests show architectural disruption compatible with a Clark's naevus. The prominent stromal reaction is also consistent. Higher-power examination revealed mild non-uniform cytological atypia. Occasional melanocytic lesions may exhibit an apparent horizontal orientation either due to the thinness of the dermal component or possibly as a result of its disruption.

4. Naevoid melanoma with spindle cell morphology

5. Nodular melanoma with a spindle cell component

6. Spindle cell melanoma

\section{Neuroidal naevus/melanocytic naevus with neurotisation}

Over time, certain melanocytic naevi may undergo a form of cytological maturation where they transform into Schwannian cells (ie, type C naevomelanocytes) ${ }^{34} 57$ (figure 4A,B). These cells have bland wavy nuclei surrounded by a pale loose, occasionally mucinous or fibrotic stroma reminiscent of neural structures. Furthermore, the cells may be arranged in tactoid formations ('Wagner-Meissner corpuscles') further suggestive of a neural origin. ${ }^{21}{ }^{31}$ Mast cells may also be increased in these areas. Often these changes are only focal in the overall lesion with more characteristic type A or type B naevomelanocytes also present, often more superficially. Occasionally, the neurotisation may be complete or near-complete, making differentiation of the lesion from a neurofibroma difficult. ${ }^{30}{ }^{31}$ Nerve fascicle-like or even Verocay body-like structures may be observed in occasional cases. ${ }^{58}$ Immunohistochemical staining for myelin basic protein, CD57 or glial fibrillary acid protein may be discriminating features in uncertain cases, with positivity favouring neurofibroma or possibly another neural lesion. ${ }^{21} 58$ Pigment is rarely expressed in such lesions and S100 is non-discriminatory. More specific melanocytic markers are generally not preserved in type $\mathrm{C}$ naevomelanocytes, as they typically do not exhibit melano- somes or tyrosinase activity. ${ }^{35}$ Ultrastructurally, neurotised naevic cells do not show true Schwannian differentiation because of a lack of axonal or mesaxonal structures, and may reveal the rare melanosome. ${ }^{34} 5758$ Overall, neuroidal naevi generally are not clinically concerning, and show an overall naevoidal pattern lacking any atypical cytological or architectural features, and so are easily recognised as benign. A junctional component to the lesion may be lacking, in contrast with the prototypical naevoidal pattern. Histopathological consideration of this form of melanocytic maturation is generally sufficient to make the diagnosis, and careful inspection for type A or $\mathrm{B}$ naevomelanocytic areas or a residual junctional component should be used to achieve greater certainty. Finally, there is no clinical utility in noting this phenomenon in the diagnostic report, and the lesion may be simply reported as 'compound naevus' or 'intradermal naevus'

\section{Congenital naevi with spindle cell component}

Congenital melanocytic naevi may be evident in one of two ways: (1) clinical history of a congenital (or tardive congenital) pigmented lesion which may be stable or changing; (2) recognisable architectural features suggestive of a congenital naevus in the absence of a clinical history (ie, 'melanocytic naevus with congenital pattern'). Activated areas or proliferative nodules may account for the clinical history of a 'changing naevus', but, of course, so can the development of a melanoma arising within 
Table 4 Melanocytic lesions that characteristically or occasionally show a spindle cell cytomorphology

\begin{tabular}{|c|c|c|}
\hline & Lesions that characteristically or commonly show spindle cells & Lesions that occasionally show spindle cells \\
\hline \multirow[t]{4}{*}{ Naevoidal pattern } & Neuroidal naevus & Congenital naevus \\
\hline & Naevus with desmoplasia & Naevi of special sites \\
\hline & Spindle cell melanoma & Naevoidal melanoma \\
\hline & & Nodular melanoma \\
\hline \multirow[t]{5}{*}{ Spitzoid lesions } & Spitz naevus & \\
\hline & Atypical Spitz tumour & \\
\hline & Spitzoid melanoma & \\
\hline & Pigmented spindle cell naevus (of Reed) & \\
\hline & Atypical pigmented spindle cell naevus & \\
\hline \multirow[t]{11}{*}{ Intradermal proliferations } & Dermal melanocytoses & Melanocytoma \\
\hline & Common blue naevus (and variants) & Paraganglioma-like dermal melanocytic tumour \\
\hline & Cellular blue naevus & Primary dermal melanoma \\
\hline & Cellular blue naevus with Satellitic nodules & Metastatic melanoma \\
\hline & Atypical blue naevus & \\
\hline & Malignant blue naevus & \\
\hline & Deep penetrating naevus & \\
\hline & Spindle cell plexiform naevus & \\
\hline & Cutaneous neurocristic hamartoma & \\
\hline & Desmoplastic naevus/desmoplastic Spitz naevus & \\
\hline & Desmoplastic/neurotropic melanoma & \\
\hline \multirow[t]{9}{*}{ Horizontally oriented lesions } & Clark's naevus with Spitzoid morphology ('SPARK' naevus) & Clark's naevus ('dysplastic' naevus) \\
\hline & Melanoma in situ of the solar type ('lentigo maligna') & Recurrent naevus phenomenon \\
\hline & Melanoma of the solar type ('lentigo maligna melanoma') & Sclerosing naevus with pseudomelanomatous features \\
\hline & & Traumatised or treated naevi \\
\hline & & Naevi associated with inflammatory dermatoses \\
\hline & & Melanoma in situ \\
\hline & & Superficial spreading melanoma \\
\hline & & Acral lentiginous melanoma \\
\hline & & Vulvar melanoma \\
\hline Mixed pattern lesions & Combined naevus & \\
\hline Undefined pattern lesions & & $\begin{array}{l}\text { Melanocytic lesion of undetermined malignant } \\
\text { potential ('MELTUMP') }\end{array}$ \\
\hline
\end{tabular}

a congenital naevus. ${ }^{59} 60$ Architectural features that are suggestive of a congenital naevus include larger size (although congenital naevi may also be small), a diffusely infiltrative horizontal component of naevomelanocytes, a deeply penetrating component involving the lower third of the reticular dermis or even the subcutis, and prominent extension of lesional cells along adnexal and neurovascular structures. ${ }^{30} 3156$ Often, congenital naevi show lesional cells herniating into dilated lymphovascular spaces simulating vascular invasion. Congenital naevi also have a great capacity for heterologous morphology, including neuroidal differentiation and spindle cell morphology ${ }^{3135}$ (figure 4C,D). Variants of congenital naevi may be entirely spindled, may show prominent neurotisation suggestive of a neural lesion (as per the neuroidal naevus phenomenon-see above), may show blue naevus-like morphology, or may show cellular proliferative nodules or clonal areas with a spindle cell morphology. ${ }^{31} 59$ Melanisation may be preserved in the spindle cell component of a congenital naevus, aiding histogenetic determination. Assessing the biological potential of congenital melanocytic naevi may be difficult because of the possible presence of mild cytological atypia, nucleoli, architectural irregularities and limited mitotic activity which may be seen in some cases, either diffusely within the lesion or focally within a proliferative nodule. ${ }^{16} \quad 5961$ Compounding the difficulty is the potential preanalytical bias that may exist with the clinical picture of, often, a large lesion that is potentially changing and the knowledge that congenital naevi (especially giant congenital naevi) are relatively fertile ground for the development of melanoma. ${ }^{61}$ Confound this further with the presence of a heterologous spindle cell morphology, either in part or whole, and the lesion may just be too disconcerting. Nevertheless, it should be recognised that all of these features are acceptable benign features of a congenital naevus which lacks aggressive/malignant potential. Assessment of biological potential must therefore rely on more established features of atypicality: uniform moderate-severe cytological atypia with prominent macronucleoli, confluent and irregular growth, destructive expansile or infiltrative growth including surface ulceration and necrosis, pagetoid activity (except in infants), lack of maturation, prominent dermal mitotic activity especially in the deeper portions of the lesion, etc. Proliferative nodules in congenital naevi are recognised by the relative rarity of mitoses (and the low proliferative index), evidence of maturational blending with surrounding naevic cells, and the lack of necrosis or destructive expansile growth. ${ }^{16} 5961$ Cytological atypia is variable but usually low grade, although significant pleomorphism can be seen. Nevertheless, the biological potential of proliferative nodules, although seemingly benign, is not fully known, and we do recommend excision of such lesions when clinically feasible. Melanoma may arise in small-medium-sized congenital naevi (as well as acquired naevi), but typically does so in the junctional component, recapitulating the pattern of a superficial spreading or nodular melanoma with overt malignant features. ${ }^{30}$ Large congenital naevi may occasionally demonstrate malignant degeneration in the form of a dermal nodule. The malignant nature of melanomas arising within congenital naevi may be inferred from an expansile and destructive nodule, with abrupt demarcation from the surrounding lesion and often extension into the subcutaneous tissue with or without prominent tumoural necrosis, and a marked increase in mitotic activity. ${ }^{59} 61$

\section{Naevi of special sites}

Part of the appreciation of the biological diversity of melanocytic lesions has occurred as a result of the recognition that certain histopathologically disturbing melanocytic lesions may predictably behave in a benign manner (see figure 8 of Part II). ${ }^{21 a}$ Such clinicopathological correlation led to the recognition that benign naevi present in certain sites may exhibit histological features that normally connote an aggressive biological potential. The 
Figure 4 Compound naevoidal pattern lesions. (A) Neuroidal naevus (H\&E;

$100 \times)$. Observe the preservation of an overall 'naevoidal' pattern (although no junctional component is appreciated) in this lesion clinically suspected to be an intradermal naevus removed from the shoulder of a 56-year-old woman. (B) Neuroidal naevus (H\&E; 400×). Highpower examination highlights the neuroidal cytomorphology and the tactoid body formations. (C) Congenital naevus with spindle cell nodule (H\&E; $50 \times)$. This congenital naevus removed from the back of a 22-year-old woman revealed numerous spindle cell areas including this nodule. (D) Congenital naevus with spindle cell nodule (H\&E; $200 \times)$. Observe the bland

cytomorphology of another spindle cell nodule and observe the more classic epithelioid naevomelanocytic nests present superficial to the nodule. (E) Naevoid melanoma with spindle cell morphology (H\&E; $25 \times$ ). This spindle cell melanocytic lesion presented as a changing lesion in a 45-year-old man. Notice the relative preservation of a naevoidal appearance, however, with an expansive and confluent dermal component. A prominent inflammatory reaction is also observed. (F) Naevoid melanoma with spindle cell morphology (H\&E; 400×). High-power evaluation reveals the relative banal appearance of the spindled lesional cells. This focus also shows the presence of small but moderately atypical epithelioid melanocytes more recognisable as naevoid melanoma. This component was very limited and not seen in all sections. Lymphatic space invasion was also present (not shown) confirming the malignant nature of this lesion.
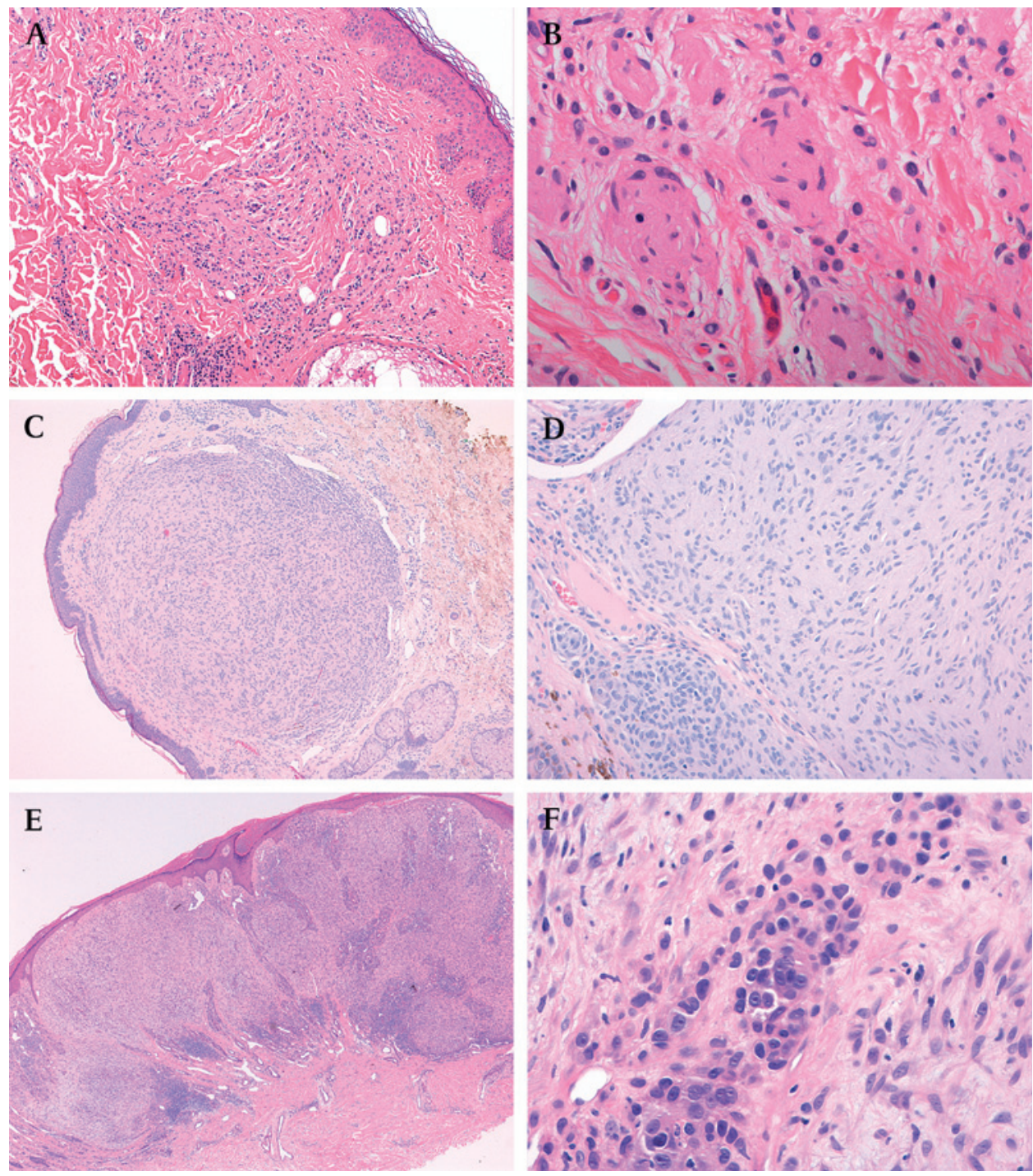

most classic and well defined of these special sites are acral locations ${ }^{16} 62-65$ and the vulva. ${ }^{16} 626667$ The male genitalia, anorectal region and perineum may also be considered 'genital sites', with features akin to vulvar naevi; however, these sites are not as well studied. Other recognised special sites include the breast, $^{68}$ flexural sites ${ }^{69}$ (ie, axilla, umbilicus, inguinal region, popliteal fossa or any other site that exists in a tissue fold such as the neck skin or abdominal folds), the ear ${ }^{70} 71$ and scalp. ${ }^{72}$ For most of these regions, chronic irritation of the lesion appears to be the most theoretically consistent explanation for the unusual features. Alternatively, hormonal factors have also been put forward as a possible explanation, albeit with some scepticism. The conjunctiva represents a non-cutaneous special site. ${ }^{62} 7374$ Spindling may be seen in naevi from special sites, and, in

Table 5 Atypical histological features characteristic of naevi from special sites

\begin{tabular}{|c|c|c|c|c|c|c|c|c|c|c|}
\hline \multirow[b]{2}{*}{$\begin{array}{l}\text { Special } \\
\text { site }\end{array}$} & \multicolumn{2}{|c|}{ Architectural distortion } & \multirow[b]{2}{*}{$\begin{array}{l}\text { Lentiginous } \\
\text { growth }\end{array}$} & \multirow[b]{2}{*}{$\begin{array}{l}\text { Pagetoid } \\
\text { spread }\end{array}$} & \multirow[b]{2}{*}{$\begin{array}{l}\text { Cellular } \\
\text { dyscohesion }\end{array}$} & \multirow[b]{2}{*}{$\begin{array}{l}\text { Cytological } \\
\text { atypia }\end{array}$} & \multirow[b]{2}{*}{$\begin{array}{l}\text { Dermal mitotic } \\
\text { activity }\end{array}$} & \multirow[b]{2}{*}{$\begin{array}{l}\text { Stromal } \\
\text { reaction* }\end{array}$} & \multirow[b]{2}{*}{$\begin{array}{l}\text { Spindled } \\
\text { morphology }\end{array}$} & \multirow[b]{2}{*}{$\begin{array}{l}\text { Major differential } \\
\text { diagnosis }\end{array}$} \\
\hline & $\begin{array}{l}\text { Irregular/confluent } \\
\text { junctional nests }\end{array}$ & $\begin{array}{l}\text { Dense dermal } \\
\text { growth }\end{array}$ & & & & & & & & \\
\hline Acral & ++ & - & ++ & ++ & - & \pm & - & + & + & $\begin{array}{l}\text { Acral lentiginous } \\
\text { melanoma }\end{array}$ \\
\hline Vulvar & + & ++ & + & \pm & ++ & ++ & + & ++ & + & Nodular melanoma \\
\hline Breast & + & - & - & + & - & + & - & + & \pm & $\begin{array}{l}\text { Superficial spreading } \\
\text { melanoma }\end{array}$ \\
\hline Flexural & + & - & - & + & \pm & + & - & + & \pm & $\begin{array}{l}\text { Superficial spreading } \\
\text { melanoma }\end{array}$ \\
\hline $\begin{array}{l}\text { Ear and } \\
\text { scalp }\end{array}$ & + & - & + & + & + & + & - & + & \pm & $\begin{array}{l}\text { Superficial spreading } \\
\text { melanoma }\end{array}$ \\
\hline
\end{tabular}

*Stromal reaction pattern is usually present as papillary dermal fibroplasia (concentric, lamellar) with an inflammatory infiltrate. However, in vulvar naevi the stromal reaction may be inconspicuous or have a unique pattern showing a broad zone of eosinophilic fibrosis involving much of the dermis \pm a variable inflammatory infiltrate.

- , unusual feature; \pm , rare or occasional feature; + , common feature; ++ , characteristic feature. 
particular, is notably a feature of vulvar naevi. ${ }^{62}$ Spindling on its own is not a feature that raises the potential risk of a lesion. Such an analysis requires evaluation of standard features with an understanding of the permissible site-related atypia (table 5).

Clinically, naevi of special sites are generally small with a banal appearance, but may occasionally show some heterogeneity in coloration, an asymmetrical profile and lack of good circumscription. Lesions tend to be stable, often over a long period of time. Spontaneous ulceration, pruritic change or a change in size or coloration may herald more ominous clinical events, warranting excision and pathological assessment. The histology of naevi removed from special sites is indistinguishable from naevi removed from other sites in most cases. However, occasional cases do show a range of architectural and histological features that deviate from the norm, features that are generally associated with melanoma (table 5). The most well recognised of these features is the possible presence of pagetoid ascension of cells. This is a well-established phenomenon in acral naevi, probably due to chronic irritation of lesions in such sites. In fact, the term 'MANIAC' (melanocytic acral naevus with intraepithelial ascent of cells) has been proposed to raise awareness of the possible occurrence of pagetoid activity in an otherwise benign acral naevus. ${ }^{75}$ Clues as to the benign nature of the pagetoid activity in naevi from special sites are the concurrent presence of melanocytic nests undergoing transepidermal elimination, a preferential syringotropic localisation of the pagetoid activity, and the presence of pigment in the stratum corneum. ${ }^{62}$ Pagetoid cells should be banal and should not show mitotic activity. Architecturally, naevi from special sites are small and have a symmetrical and well-circumscribed silhouette; however, this may not be appreciated depending on the completeness of excision and the sectioning of the lesion. Lesions generally show bland cytology, a lack of mitotic activity and evidence of maturation; however, irritative effects may induce changes in all three of these parameters. In cases where such features are present, they need to be interpreted within the context of the remainder of the lesion. As always, multiple dermal mitoses (especially when located deeply), high-grade cytological atypia and a complete lack of maturation are all concerning features that should trigger complete excision of a lesion. A rare mitosis or mild cytological atypia may be acceptable within an otherwise small and symmetrical lesion with no evidence of confluent growth. Vulvar naevi, however, may notably show cytological atypia, and often an alarming degree of dermal growth including occasional mitoses. Clark et al ${ }^{76}$ originally described three abnormal architectural patterns of vulvar naevi: (1) the 'nested' pattern; (2) the 'dyshesive nest' pattern; and (3) the 'crowded' pattern. However, lesions often show overlapping patterns. Clinical parameters are crucial in such cases, as the threshold for diagnosing a melanoma in a young patient should be very high because of its extreme rarity. In contrast, a vulvar melanocytic lesion should be eyed suspiciously in an older patient if it has worrisome clinical or histological features. Vulvar melanomas tend to present as clinically evolving lesions in postmenopausal women, with a histological picture of a crowded lentiginous proliferation of atypical melanocytes. ${ }^{66}$ This is in contrast with the more typical dermal proliferation and young patient age for vulvar naevi. Prominent lentiginous growth is, however, a feature that may be seen in naevi from special sites, even to the point of apparent confluence. A stromal response is also commonly encountered in naevi from special sites and includes papillary dermal fibroplasias (both lamellar and concentric), and occasionally a unique diffuse pattern of dermal fibrosis which may be confused with desmoplasia or regression. ${ }^{62}{ }^{66}$ Recogni- tion and proper assessment of the site-related deviant cytological and architectural features, particularly when taken in the context of the patient's age and other clinical parameters, is crucial in order to avoid the systematic overcalling of biologically inert lesions biopsied from such sites. Conversely, recognition of the site-related atypia phenomenon may also lead to undercalling of truly atypical lesions.

\section{Naevoid melanoma with spindle cell morphology}

Naevoid melanoma is a challenging diagnosis in melanocytic pathology. The term is relatively poorly defined, but may be used to encompasses a heterogeneous histological spectrum of malignant melanocytic lesions ranging from those histologically unrecognisable as malignant but which subsequently behave in a malignant manner ${ }^{77}$ to those atypical melanocytic lesions composed of small (albeit atypical) 'naevoidal' melanocytes arranged in an overall pattern suggestive of a naevus but which display features that are concerning enough to warrant the label of melanoma ${ }^{78-80}$ (figure $4 \mathrm{E}, \mathrm{F}$ ). Naevoid melanomas may be encountered in both young and old patients, often as a moderately sized tan nodule which may be verruciform in some cases (verruciform pseudonaevoid melanoma ${ }^{81}$ ). Although classically epithelioid in morphology, spindle cell naevoid melanomas may also be encountered. ${ }^{78}$ Such lesions may often be recognised by the presence, albeit subtle, of cytological atypia, mitotic activity and irregular, often somewhat confluent, growth. ${ }^{16}{ }^{17}$ Commonly, the most telling feature is a large nodule with an expansile front that may reach or extend into the subcutis. In addition, there is generally no evidence of maturation. Ancillary immunohistochemical staining with HMB-45 and MIB-1 may further highlight the atypicality, increased proliferative rate, and lack of maturation of these lesions. ${ }^{78} 80$ Needless to say, any melanocytic lesion, particularly in the setting of a new or changing lesion or one in an older patient, should be carefully scrutinised for malignant features. Although low-power examination reveals a variable degree of distortion of an underlying benign-appearing silhouette as well as a variable degree of cytological enlargement, hyperchromasia and nuclear atypia, close high-power scrutiny is generally the key to recognition and ultimate diagnosis. Evaluation of the biological potential of a naevoidal lesion should follow a standard approach to melanocytic lesions (table 3). Intradepartmental or external consultative opinions may be sought in challenging cases.

\section{Nodular melanoma with a spindle cell component}

By definition, nodular melanoma is a neoplastic proliferation of malignant melanocytes exhibiting a vertical growth phase in the absence of a horizontal growth phase. ${ }^{82} \mathrm{~A}$ horizontal growth phase is considered to be present when the intraepidermal/ junctional component of the lesion does not extend peripherally more than three adjacent rete ridges beyond the dermal component of the nodule. Such lesions probably arise from the rapid development of a melanoma into an invasive phenotype thereby avoiding a prolonged precursor horizontal growth phase. Clinically, nodular melanomas are a relatively common subtype of melanoma seen more often in older people. Lesions are characteristically rapid-growing dark nodules or polyps that commonly ulcerate and crust. Amelanotic forms are also known. Histologically, nodular melanomas preserve a compound naevoidal pattern, although, not uncommonly, ulceration obliterates the majority of the epidermal component. When preserved, the epidermis reveals an in situ component, which may reveal pagetoid activity. By definition, lesions are circumscribed (in the horizontal plane) and also generally maintain 
a relatively symmetrical silhouette. The lesions are often of moderate-large size, with destructive expansile growth, dense confluence of cells, lack of dermal maturation and variable cytological atypia. Mitotic activity is generally appreciable and often high. This may further be highlighted by Ki67 or MIB-1 labelling. Spindling can be seen, and may even be the prominent cytomorphology. However, epithelioid areas are generally also present to varying extents. ${ }^{8}$ Uniform spindling in an otherwise nodular melanoma overlaps with the generic term 'spindle cell melanoma' (see below). Spindle cell nodular melanomas are generally not difficult to diagnose. Deviant clinical, architectural and cytological features generally allow easy recognition of its malignant nature. Occasional cases may exhibit less pronounced aggressive features, but careful scrutiny usually will reveal sufficient dermal mitoses, appreciable cytological atypia or other features to permit diagnosis. In such cases, an increased proliferative fraction or immunohistochemical demonstration of a lack of maturation (eg, diffuse HMB-45 staining) may offer some assistance in diagnosis. A careful search for residual epithelioid areas, particularly in the junctional/superficial areas, helps eliminate consideration of non-melanocytic entities in challenging cases. Efforts to develop other antibodies in the diagnosis of melanoma are ongoing, with WT-1 43475483 and nestin ${ }^{51-53} 84$ offering two potential aids in the determination of melanomas. However, the reliable utility of these antibodies has not yet been fully established.

\section{Spindle cell melanoma}

The generic term 'spindle cell melanoma' refers to a malignant melanocytic lesion with a uniform spindle cell cytomorphology. In many cases, such lesions are, in fact, nodular melanomas with complete spindled morphology. Both acral melanomas and melanomas of the solar type ('lentigo maligna melanoma') also often exhibit a spindled morphology. Both of these are generally easily recognised despite their cytomorphology on clinical and other histopathological grounds. In such cases, these terms are preferred, and we generally do not use the diagnostic term 'spindle cell melanoma' except when more precise resolution cannot be attained. The true challenge in most cases is in distinguishing such lesions from non-melanocytic spindle cell lesions (table 1). This requires careful histological scrutiny of the lesions for evidence of melanocytic differentiation (box 1) or evidence of another form of differentiation, as well as immunohistochemical confirmation (S100, other melanocytic markers, negativity for markers suggestive of other entities in the differential diagnosis). Challenging cases may arise, particularly since the more specific melanocytic immunostains are often negative in spindle cell melanomas. Multiple antibodies should be used, as occasionally MiTF or tyrosinase will show positivity despite the absence of staining with HMB-45 and Melan-A. WT-1 expression may offer some support to a presumptive diagnosis of melanoma, although its specificity is lower than that of the aforementioned stains. We do not consider S100 positivity alone to be definitive evidence of melanoma in cases that lack other evidence of melanocytic differentiation (nesting pattern, melanin production, junctional component, other immunohistochemical evidence, background melanocytic lesion). S100 positivity is also seen in neural lesions (although MPNSTs are generally only focally S100 positive and often negative). Langerhans cell lesions are also S100-positive lesions and may reveal misleading pagetoid spread. ${ }^{14} 85$ Atypical fibroxanthomas and cellular dermatofibromas may show scattered S100-positive Langerhans cells. ${ }^{29}$ We have also seen three cases of interdigitating dendritic sarcomas misdiagnosed as melanomas on the basis of their diffuse S100 positivity. Clinical correlation is often crucial in resolving such issues. Ultrastructural studies may also provide additional support for or against spindle cell melanoma in challenging situations (box 1).

\section{Spitzoid lesions}

The next group of recognisable spindle cell melanocytic lesions is the Spitzoid family (refer to Box 3 for notable pitfalls). The name 'Spitzoid' represents a distinct architectural and cytological pattern, which, when present in the classical form, is readily identifiable (figures $3 \mathrm{~B}$ and 5 and table 6). Spitzoid lesions are classically well-circumscribed, symmetrical lesions that may be junctional, compound or, rarely, intradermal. ${ }^{30} 3186$ Compound lesions may extend deep into the dermis often in a subtly infiltrative manner, and often with discrete isolated cells or small nests present deep to the main body of the tumour ('outlier cells'). ${ }^{30}$ Spitzoid lesions by definition are composed of enlarged spindled and/or epithelioid melanocytes that typically show nucleoli and a variable degree of cytological atypia. ${ }^{87} 88$ Multinucleation is commonly encountered in Spitzoid lesions, and nuclei characteristically show angulations and geometric forms. Cells may also fit together creating geometrical patterns. Significant eosinophilic cytoplasmic substance generally preserves a low N/C ratio in lesional cells, and may reveal a bluish tinge. Classically, Spitzoid lesions are amelanotic or hypopigmented, although hyperpigmented variants do exist. Architecturally, Spitzoid lesions may show pagetoid activity even when benign. As well, limited superficial dermal mitotic activity is permissible in benign Spitzoid lesions, although deep dermal mitoses, atypical mitoses or clustering of mitotic figures remain atypical features. ${ }^{86}$ Spitzoid lesions are notorious for their histological overlap with melanoma, highlighted by the historic use of the outdated term 'benign juvenile melanoma' for classic Spitz naevi. The fact that Spitzoid lesions are more commonly encountered in younger populations ( $<20$ years) compounds the need for caution in the pathological interpretation of these lesions. Fortunately, recognition of Spitzoid lesions may be aided by additional characteristic histological features including epidermal hyperplasia surrounding the junctional nests, a vertical ('raining down') orientation of junctional nests, the presence of intraepidermal eosinophilic globules ('Kamino bodies'), and artifactual stromal retraction around junctional nests ('semilunar clefts'). ${ }^{30} 318689-91$ The utility of identifying Spitzoid morphology is in the recognition that certain otherwise concerning histological features may not be indicative of aggressive biological potential.

On the other hand, there are persistent concerns regarding Spitzoid lesions, in particular, the lack of pathological criteria to assuredly determine benignancy in a Spitzoid lesion. ${ }^{92-98}$ Clinical follow-up of classic lesions in most cases reveals a benign course. Yet rare cases, particularly with the accumulation of atypical

Box 3 Notable challenges/pitfalls in the evaluation of Spitzoid melanocytic lesions

Spitz tumours versus melanoma.

Placement of Spitzoid lesions on the Spitz naevus-atypical Spitz naevus-Spitzoid melanoma spectrum.

Pigmented spindle cell naevus of Reed versus Clark's naevus. Pigmented spindle cell naevus of Reed versus melanoma in situ/ superficial spreading melanoma. 

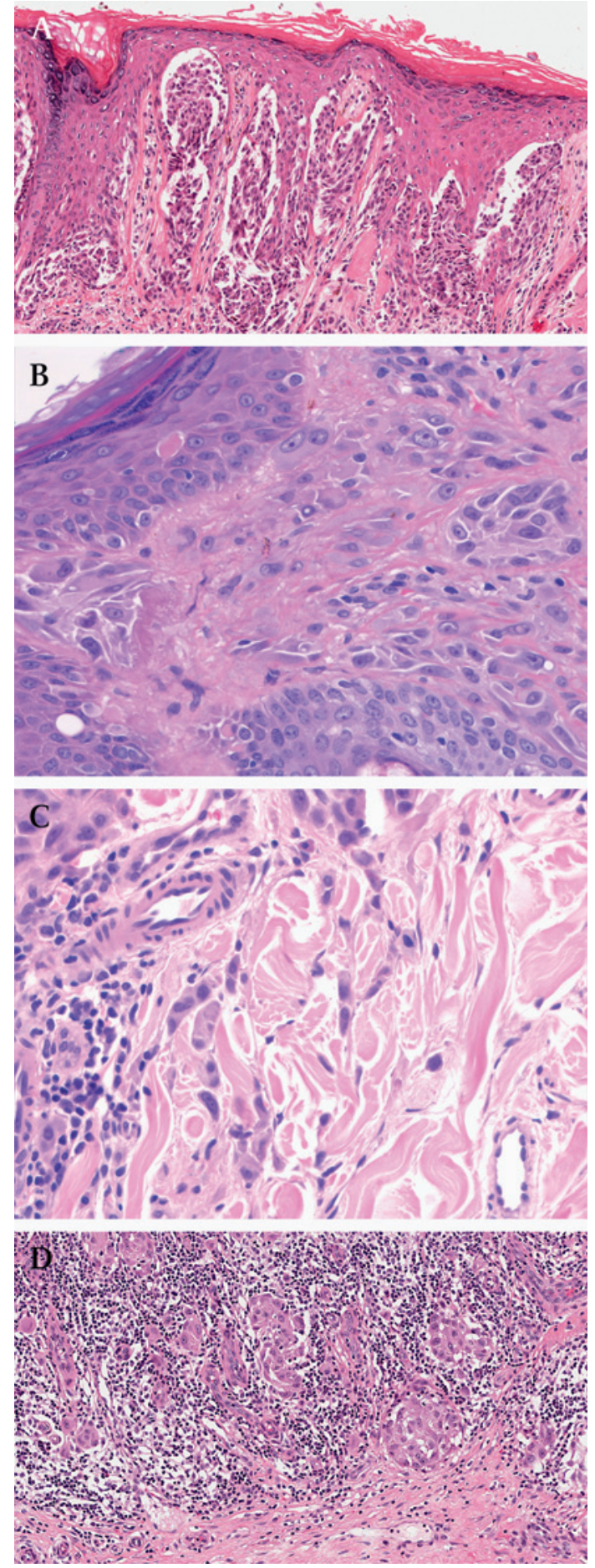

Figure 5 Histological features that characterise Spitzoid lesions. (A) Epidermal features (H\&E; $200 \times$ ). This compound Spitz naevus (16-yearold boy; lower back) shows epidermal hyperplasia with hypegranulosis surrounding nests of epithelioid and spindled Spitzoid melanocytes with a vertical orientation. Artifactual clefting around junctional nests ('semilunar clefting') is well appreciated. Kamino bodies and mild pagetoid activity are also present. A single junctional mitotic figure is also noted. (B) Cytological features (H\&E; $400 \times$ ). Classic Spitzoid cytomorphology is revealed in this compound Spitz naevus (27-year-old woman; nose). Enlarged amelanotic melanocytes with spindled, epithelioid, and intermediate cytomorphologies can be seen. The N/C ratio is low due to the presence of abundant cytoplasmic substance which displays a bluish tinge. Cytological atypia are moderate with angulated nuclei and moderate pleomorphism. Nucleoli are prominent. However, there is no significant hyperchromasia, chromatin is dispersed, features, still have unexpected clinical outcomes, from the presence of sentinel node deposits but an otherwise benign course to disseminated metastases and death. ${ }^{96} 97$ 99-105 This uncertainty has led some to prefer usage of the term 'Spitz tumour' to 'Spitz naevi' for all except perhaps only the most classic cases of Spitz naevi. ${ }^{96}$ As a result, Spitz naevi are ideally completely excised when it is clinically feasible. ${ }^{21} 9296$ This is also required since proper pathological evaluation must assess a lesion in its entirety because of the extreme importance of assessing the lesion's silhouette to identify its Spitzoid nature and form an estimate of its biological potential. Atypical lesions must be managed more conservatively. Furthermore, there has been some evolution of the concept of the Spitz naevus from a mainly paediatric melanocytic tumour, with histological features overlapping those of adult melanoma, but with an almost certain benign course when showing classical features, to a morphological entity recognised not only in children but also in adults, in which the concern for mistaken identity becomes more significant, particularly when there is partial deviation from the classical phenotype. Appropriate evaluation of Spitzoid lesions thus needs to proceed in two parallel ways (figure 6):

1. Histopathological assessment of the lesion in order to assess atypical features and thus grade the degree of atypia, placing the lesion on a poorly defined spectrum of Spitzoid lesions (ie, is it an atypical lesion?)

2. Clinical assessment of the lesion (ie, age, location, colour, size, silhouette) in order to best predict the pretest probability that the lesion is, in fact, a melanoma, regardless of histological features (ie, is it a borderline lesion?)

Assessment of the clinical parameters adjusts the thresholds for translating the extent of deviation from a classical Spitz phenotype to a specific diagnosis. For example, there should be great resistance to diagnosing a Spitz naevus in an older patient because of the significant risk that the lesion is a melanoma with Spitzoid features. ${ }^{86}$ In contrast, in a child, one should be wary before diagnosing a Spitzoid lesion with highly deviant features as a melanoma unless truly convincing malignant features are present. Needless to say, such a lesion should certainly be diagnosed in a manner that reflects its atypicality, its potential for aggressive behaviour, and the histopathological limits to ruling out a melanoma. Juvenile melanomas do certainly exist, and many tragic cases attest to the potential malignant behaviour of atypical melanocytic lesions in the paediatric population. Furthermore, it should be emphasised that the ultimate diagnosis should not be based on the pretest probability of the lesion representing a melanoma (ie, essentially the relative incidence of the lesions in the differential diagnosis) but rather the post-test probability that the lesion will behave in a biologically

[Continued]

and nuclear membranes are regular, consistent with a benign Spitz naevus. Multinucleation is noted in occasional cells. A small Kamino body is also noted in the epidermis. (C) Dermal architecture (H\&E; $400 \times$ ). The deep aspect of this compound Spitz naevus (same lesion as in (B)) reveals an infiltrative pattern with the presence of 'outlier' cells at a distance from the apparent front of the lesion. Architectural and cytological maturation of the lesional cells are apparent. (D) Atypical Spitzoid features (H\&E; $200 \times$ ). This atypical Spitz tumour (46-year-old woman; lower leg) showed a characteristic Spitzoid silhouette (small size, symmetry and circumscription) and cytomorphology. Concern for the lesion centred around its prominent epithelioid morphology (in an adult) and the lack of architectural or cytological maturation (note the large nests towards the deep front of the lesion). The prominent inflammation is also somewhat unusual. Sentinel lymph node biopsy was negative. 
Table 6 Features of Spitzoid lesions

\begin{tabular}{|c|c|c|c|}
\hline Feature & Spitz naevus & Atypical Spitz tumour & Spitzoid melanoma \\
\hline \multicolumn{4}{|l|}{ Clinical } \\
\hline Age & Any age $(2 / 3<20$ years $)$ & No difference & No difference \\
\hline Location & $\begin{array}{l}\text { Any location (extremities and trunk } \\
\text { preferred; H\&N in children) }\end{array}$ & No difference & No difference \\
\hline Colour & Red-brown; occasionally pigmented & No difference & No difference \\
\hline \multicolumn{4}{|l|}{ Silhouette } \\
\hline a. Size & Small (most $<6 \mathrm{~mm}$ ) & Variable & Large (>10 mm) \\
\hline b. Symmetry & Present & Variable & Asymmetrical \\
\hline c. Circumscription & Present & Variable & Poor \\
\hline Evolution/clinical course & Stable & $\begin{array}{l}\text { May metastasise to regional LNs; natural } \\
\text { history uncertain }\end{array}$ & $\begin{array}{l}\text { Variable malignant course: regional LN } \\
\text { mets but favourable outcome to widely } \\
\text { metastatic disease and death }\end{array}$ \\
\hline \multicolumn{4}{|l|}{ Architectural } \\
\hline \multicolumn{4}{|l|}{ Epidermis } \\
\hline \multicolumn{4}{|l|}{ Silhouette } \\
\hline a. Size & Small & Variable & Large \\
\hline b. Symmetry & $\begin{array}{l}\text { Present (must evaluate fully excised } \\
\text { lesion) }\end{array}$ & Variable & Asymmetrical \\
\hline c. Circumscription & $\begin{array}{l}\text { Present (must evaluate fully excised } \\
\text { lesion) }\end{array}$ & Variable & Poor \\
\hline Epidermal hyperplasia & Present & No difference & May be atrophic/ulcerated \\
\hline Artifactual clefting & Present & No difference & Variable \\
\hline Kamino bodies & $\begin{array}{l}\text { May be present ( } \sim 50 \% \text { of } \\
\text { cases-multiple levels increase } \\
\text { detection) }\end{array}$ & No difference & No difference \\
\hline Pagetoid spread & Often present & Variable & $\begin{array}{l}\text { Prominent; present at edge of lesion or } \\
\text { upper half of epidermis }\end{array}$ \\
\hline \multicolumn{4}{|l|}{ Dermis/subcutis } \\
\hline Cellular density & Variable (low-moderate) & Moderate- dense & Dense (confluent growth) \\
\hline Pattern of growth & Organised, nested and interstitial growth & Variable & Confluent, destructive \\
\hline Architectural maturation & Present & Variable & Absent \\
\hline Deep front of lesion & Infiltrative with outlier cells & Variable & Expansile or infiltrative \\
\hline Involvement of subcutis & Rare-may be minimal & Variable & May be pronounced \\
\hline Stromal/inflammatory response & Variable (usually mild) & Variable & Inflammation or regression may be noted \\
\hline \multicolumn{4}{|l|}{ Cytological } \\
\hline Nuclear size & Moderate-large & No difference & Large \\
\hline Nuclear shape & Normal-angulated & No difference & Pleomorphic \\
\hline Cytoplasm & Abundant, eosinophilic 'ground-glass' & No difference & Variable \\
\hline $\mathrm{N} / \mathrm{C}$ ratio & Low & No difference & Variable \\
\hline Multinucleation & Present & No difference & No difference \\
\hline Hyperchromasia & Low-moderate & Variable & High \\
\hline Nucleoli & Present (small-moderate sized) & Variable & Present (large) \\
\hline Nuclear membrane & Normal & Variable & Irregular \\
\hline Chromatin pattern & Dispersed & Variable & Coarse \\
\hline Cytological maturation & Present & Variable & Absent \\
\hline \multicolumn{4}{|l|}{ Other } \\
\hline Mitotic activity & $\begin{array}{l}\text { Absent-moderate (up to } 6 \text { per } 10 \mathrm{hpf} \text { ); } \\
\text { confined to junction or superficial dermis }\end{array}$ & Variable & $\begin{array}{l}\text { High (often }>6 \text { per } 10 \mathrm{hpf} \text { ); abnormal or } \\
\text { deep forms }\end{array}$ \\
\hline Perineural or angiolymphatic invasion & Absent & Absent & May be present \\
\hline Sentinel lymph node & Negative & May be positive & May be positive \\
\hline Necrosis & Absent & Absent & May be present \\
\hline \multicolumn{4}{|l|}{ Immunohistochemistry } \\
\hline HMB-45 & Variable (typically stratified) & Variable & Variable (often diffuse) \\
\hline MIB-1 & Low proliferative index $(<10 \%)$ & Variable $(<15 \%)$ & High $(>15 \%)$ \\
\hline Cytogenetics & Normal or isolated gain of $11 p$ & Intermediate-often complex aberrations & Complex chromosomal aberrations \\
\hline
\end{tabular}

H\&N, head and neck; LN, lymph node.

aggressive manner (ie, the probability that the lesion is a melanoma or other aggressive lesion based on histopathological assessment and accounting for the pretest probability).

Efforts to resolve these issues are ongoing, with promising cytogenetic work that may allow differentiation of Spitz naevi from Spitzoid melanoma based on the extent and types of chromosomal abnormalities observed. ${ }^{106-109}$ Spitz naevi may reveal a normal karyotype, but, not uncommonly, reveal a unique copy number increase of the small arm of chromosome 11. Melanomas tend to show complex cytogenetic anomalies including chromosomal losses of $6 p, 8 p, 9 p$ and $10 q$, as well as copy number increases in chromosomes 1q, 6p, 7, 8q, 17q and $20 \mathrm{q}$. Thus the unique nature of the 11p gain in Spitz naevi, which is not typically seen in melanoma, as well as the complex chromosomal aberrations seen in melanoma as opposed to the absent or minimal chromosomal aberrations seen in Spitz naevi (or other 
naevi for that matter) offer new cytogenetic features that may be exploited to differentiate challenging cases, or even as a standard test in the work-up of Spitzoid lesions. Clearly, clinical validation is required, but such a test would be of great value in that it would allow more accurate study of the true biological basis of such lesions and a prediction of their biological potential based on their molecular make-up. Such ancillary tests are clearly enticing given the challenge inherent to predicting the biological potential of Spitzoid lesions based on morphology alone.

The spectrum of Spitzoid lesions used in our practice include:

1. Spitz naevus (and variants) (may be junctional, compound, dermal)

2. Atypical Spitz tumour (low-grade, high-grade)

3. Spitzoid melanoma/melanoma with Spitzoid morphology

4. Pigmented spindle cell naevus (of Reed) (may be junctional or compound)

- Atypical pigmented spindle cell naevus

Spitz naevi (may be junctional, compound or intradermal)

Spitz naevi are uncommon melanocytic lesions (although often encountered in dermatopathology practice ${ }^{4}$ ), which most commonly occur on the extremities or trunk, although the head and neck region, in particular the face, is also a site of predilection in children. ${ }^{325110}$ A general rule is that one third of cases occur in children ( $<10$ years), one third in adolescents/teenagers $(10-20$ years), and one third in adults ( $>20$ years), although some studies suggest a higher proportion in adults. ${ }^{111}$ Most appear as amelanotic/hypopigmented red or red-brown macules, papules or nodules of limited size with most $<6 \mathrm{~mm}$ and almost all $<10 \mathrm{~mm}$. Rare lesions may extend up to $2 \mathrm{~cm}$. Spitz naevi are usually acquired lesions that have an initial rapid growth phase, which reaches permanent stability after about 6 months. ${ }^{86}$ Polypoid and pigmented variants do exist and are not criteria for considering the lesion atypical or for rendering an alternative diagnosis. Another clinical pattern is the agminate (multifocal) Spitz naevus. Spitz naevi may become pruritic when there is an inflammatory infiltrate, but should not ulcerate unless traumatised. Critical to the diagnosis of a Spitz naevus is its symmetry and sharp circumscription. The dermatoscopic appearance of Spitz naevi often shows a characteristic 'sun-burst' pattern.

Spitz naevi may be entirely junctional, compound (majority of cases) or intradermal. An intraepidermal pagetoid variant is also known. ${ }^{86}$ Most lesions tend to show either a papillomatous or a dome-shaped pattern with preservation of the symmetrical and circumscribed silhouette histologically. There should be no shouldering phenomenon. Spitz naevi may grow deeply, and, in such cases, typically show an infiltrating, but non-destructive pattern of growth, often with small groups of cells or single cells isolated from the main body of the tumour at its advancing edge ('outlier cells'). ${ }^{30}$ Mild-moderate pagetoid activity is acceptable in Spitz naevi, although it should be located centrally within the lesion and should not reach the granular cell layer. True pagetoid activity must be distinguished from transepidermal elimination of melanocytic nests, however, since the latter may also be present and may extend through the stratum granulosum/ corneum. Moderate mitotic activity is acceptable (up to six mitoses per $10 \mathrm{hpf}$ ) within otherwise classical Spitz naevi, although deep dermal mitoses, atypical mitoses, clustering of dermal mitoses, and mitoses in pagetoid cells remain features of concern. Rare cases of classical Spitz naevi in young children may reveal profuse mitotic activity. ${ }^{96}$ We may tolerate up to 20 mitoses per $10 \mathrm{hpf}$ provided that no further atypical features are appreciated and a classic silhouette is maintained, and have termed such lesions 'proliferating Spitz naevi'. The natural history of such lesions is unknown, but it is likely that they represent sampling of classic Spitz naevi during a proliferative phase of the lesion. Cytological and architectural maturation are important reassuring features in Spitz naevi, and a lack of maturation should be considered an alarming feature. In particular, a large deep dermal nest (ie, significantly larger than the more superficial nests) with an expansile border and no evidence of cytological maturation is of significant concern. The density of the cellular proliferation in Spitz naevi may vary; however, dense confluent growth, particularly if it is irregular or destructive, is an atypical feature. In addition to these characteristic cytological and architectural features, Spitz naevi classically show epidermal
Figure 6 Algorithmic approach to the management of Spitzoid lesions. Underlined atypical features suggest a diagnosis of high-grade atypical Spitz tumour. Bx, biopsy; HG, high grade; hpf, high-power field; LG, low grade; SLN, sentinel lymph node.

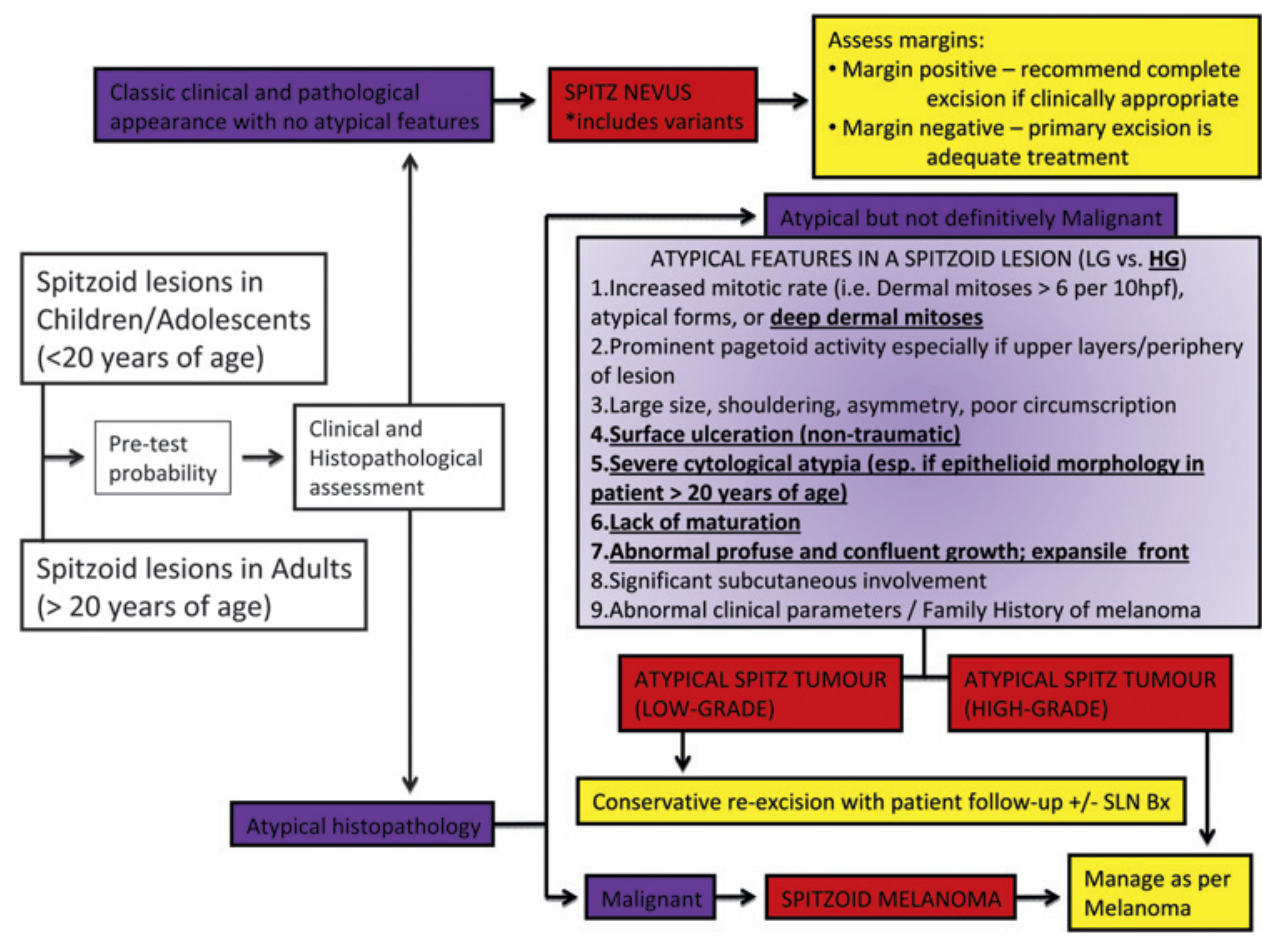


hyperplasia with elongation of the rete ridges, which give a 'clutching' appearance around the junctional nests, which often contain spindled cells in a vertical orientation likened to a bunch of bananas or imparting a 'raining down' effect. Furthermore, there is typically evidence of stromal retraction around these nests, at least in part producing the so-called 'semilunar clefts'. This appearance should be contrasted with the appearance of dyscohesive melanocytic nests, which may also give the appearance of stromal separation but with an otherwise loose dyscohesive arrangement. Dyscohesion is an atypical feature and may raise concern for a melanoma. Kamino bodies ${ }^{89} 90$ are a characteristic and fairly specific histological feature of Spitz naevi which represent amorphous PAS-positive, diastase-resistant eosinophilic globules composed of basement membrane material located at the dermo-epidermal junction. ${ }^{112} 113$ Only rarely are they found in melanomas. Kamino bodies may be absent in Spitz naevi, especially when there is limited sampling/levels. Vascular ectasia and an inflammatory component may also be seen in Spitz naevi. Spitz naevi may be present as the following histological variants: desmoplastic (refer to part II: intradermal proliferations); ${ }^{21 a}$ pigmented (pigmented spindle cell naevus; discussed below); angiomatoid (Spitz naevus with halo phenomenon); plexiform; hyalinised; myxoid; pagetoid; as a component of a combined naevus (refer to part II: combined lesions). ${ }^{21 a}$

Of paramount importance to the diagnosis of Spitz naevi is the presence of large spindled and/or epithelioid melanocytes with Spitzoid nuclear features (nucleoli, pleomorphism, angulated/geometric nuclei, multinucleation). ${ }^{19} 30 \quad 31$ 86-88 Hyperchromasia and coarsening of chromatin are not features of benign Spitz naevi. The cytoplasm of Spitz naevi is also characteristic because of its abundance, typical lack of pigmentation, and its glassy pale eosinophilic quality often with a bluish tinge. Spindled cells tend to predominate, and epithelioid variants should be viewed with suspicion when found in adult patients.

The classic cytological and architectural Spitzoid features are critical to the diagnosis (figure 4 and table 6), and thus light microscopy remains the 'gold standard' of diagnosis. Spitz naevi stain diffusely for S100 and generally show a stratified maturation pattern of staining with other melanocytic markers (eg, HMB-45). ${ }^{92}$ Proliferation index markers (eg, Ki67, MIB-1) also show greater labelling towards the surface. Numerous other immunohistochemical markers (CD99, ${ }^{50} 92$ cyclin D1, ${ }^{38} 45$ p16, ${ }^{46} 92$, c-kit, ${ }^{49} 92$ bcl-2, ${ }^{45}$ others ${ }^{45}{ }^{92}$ ) have shown positive expression in Spitz naevi, but none have reproducibly been shown to differentiate benign from malignant Spitzoid lesions. Spitz naevi tend to show limited cytogenetic abnormalities in contrast with melanomas, which tend to show a multitude of changes ${ }^{106-109}$ (discussed above). Comparative genomic hybridisation may be used to assess the cytogenetic status of lesional cells, and, if reliable discriminating cytogenetic foci are determined, routine fluorescence in situ hybridisation assays may be developed.

\section{Atypical spitz tumour}

The label 'atypical Spitz tumour' (also known as 'Spitz tumour of undetermined malignant potential' or STUMP) serves two purposes in the pathological reporting of Spitzoid lesions: (1) it highlights the significant grey zone in Spitzoid lesions in which the pathologist no longer feels comfortable promising benign biological behaviour based on clinical and pathological parameters; (2) it allows categorical placement of such lesions so that established management protocols may be followed by clinicians and for future studies on the true nature of these lesions. Compromising the latter point is the fact that this category is almost certainly a heterogeneous group of lesions, which we would ultimately wish to resolve into more appropriate diagnoses. Thus the atypical Spitz tumour category probably consists of lesions that are Spitzoid in nature as well as many lesions that are not fundamentally Spitzoid but exhibit features suggestive of a Spitzoid lesion (which, if recognised more precisely, are preferably termed 'the underlying melanocytic lesion ... with Spitzoid morphology'). Furthermore, the atypical nature may be based on deviation from architectural features (eg, loss of the classic Spitzoid silhouette, lack of architectural maturation, ulceration, confluent growth with an expansile front, extension into the subcutaneous tissue), cytological features (eg, severe cytological atypia beyond the acceptable limits for Spitz naevi, increased/ abnormal/deep mitoses), clinical features (eg, large size), or any combination of the above (eg, epithelioid morphology in an adult, prominent pagetoid activity in an adult). These features have mainly been discussed above (see Spitz naevus) and are also summarised in table 6. Confounding this category even further is the fact that, despite much effort, there are no reliable criteria to guide the placement of entities into this category, and, in essence, the task is largely left up to the individual thresholds tolerated by each pathologist. ${ }^{96} 114115$ Almost certainly, significant interobserver and potentially intraobserver variation must exist. ${ }^{97}$ However, it is certain that no effective criteria could be put forward, as, by nature, the entity is a diagnosis by exclusion (ie, not certainly a Spitz naevus and not certainly a melanoma). This highlights the final concern about the heterogeneous population of lesions within the atypical Spitz tumour group: it contains both lesions considered in the differential diagnosis of a Spitz naevus (ie, with low-grade features or considered low risk for malignant behaviour) and lesions considered in the differential diagnosis of a melanoma (ie, with high-grade features or considered at high risk for malignant behaviour). This assessment of risk is again a gestalt of the clinical and pathological attributes of the lesion without clear defining lines of separation. Nevertheless, we do use this separation to help communicate our best estimate of malignant potential for a lesion falling in the wide gap between a Spitz naevus and a melanoma. Thus we use the terms atypical Spitz tumour (low grade) and atypical Spitz tumour (high grade). Such a division is used by other groups as well. ${ }^{19} 93$ In general, severe cytological atypia particularly in prominently epithelioid tumours, multiple deep dermal mitoses, surface ulceration and loss of the classic Spitzoid silhouette, particularly if it is by a dense confluent proliferation that shows a bulging margin, are considered high-grade features. Clinical management may vary on the basis of this delineation in select cases (eg, Spitzoid lesion on the face of a young child). However, only a minority of cases of Spitzoid lesions should fall into the category of atypical Spitz tumour, with resolution of Spitz naevi and Spitzoid melanomas possible in most instances. Immunohistochemistry may be of some help in the evaluation of atypical Spitzoid lesions. ${ }^{92}$ Proliferation markers such as Ki67 or MIB-1 may highlight an increased proliferation rate and/or a lack of diminished activity in the deeper components of the lesion. HMB-45 may highlight a stratified staining pattern suggestive of maturation, although diffuse staining is not incompatible with a benign compound Spitz naevus.

Atypical Spitz tumours in children, with or without sentinel lymph node (SLN) metastases, show almost universal survival, ${ }^{114} 116$ with paediatric mortality from Spitzoid lesions occurring essentially only in cases in which the primary tumour is histologically clearly malignant (see Spitzoid melanoma below). This is at the centre of the debate whether or not SLN positivity is a criterion for a diagnosis of Spitzoid melanoma. Owing to the favourable outcome of paediatric patients whose 
primary Spitzoid lesions are indefinite for malignancy but whose SLNs are subsequently found to contain deposits/metastases, we consider such a finding compatible with a diagnosis of atypical Spitz tumour, provided that the deposit is not highly malignant appearing and does not exhibit appreciable destructive infiltration of the lymph node. Such studies also beg the question whether or not SLN biopsies are warranted for atypical Spitz tumours, particularly because of the high rate of positivity (up to 50\%). ${ }^{100-102} 104105$ However, until further study is carried out, we will continue to recommend SLN biopsy (in addition to complete excision with conservative margins of at least $1 \mathrm{~cm}$ ) for cases of Spitzoid lesions equivocal for malignancy. Atypical Spitz tumours in adult patients are not as well studied, and a more guarded prognosis is warranted.

\section{Spitzoid melanoma}

The end of the Spitzoid spectrum is Spitzoid melanoma. Spitzoid melanomas share many of the general clinical features of melanoma except that they are more common in younger patients including children. ${ }^{92} 95117$ Spitzoid melanomas may be clinically suspected in cases of Spitzoid lesions that spontaneously ulcerate or enlarge, often with disruption of the symmetrical silhouette. Large Spitzoid lesions (ie, $>10 \mathrm{~mm}$ ) are also suspect. As opposed to the termination of the initial growth phase of Spitz naevi, Spitzoid melanomas do not attain stability but continually grow and change. ${ }^{86}$ Overt signs of malignancy may include regional adenopathy or other evidence of metastatic disease. Occasionally, one or multiple Spitz naevi may arise near the place of a prior excision of a classic Spitz naevus, raising concern for satellitic metastases of a missed Spitzoid melanoma. However, such a phenomenon, when histologically benign, should be appreciated as satellitic Spitz naevi, akin to an agminated Spitz naevus, with no increased potential for malignant behaviour. ${ }^{118}$ Recurrent Spitz naevi ${ }^{119}$ may also be confused with a malignant process, and features of a recurrent naevus phenomenon should be appreciated (see part II: horizontally oriented lesions; naevi with disruption phenomena). ${ }^{21 a}$

Histological evaluation of a Spitzoid melanoma follows as per the evaluation of any other melanocytic lesion, with attention also paid to the special features of a Spitzoid lesion (eg, presence of Kamino bodies, characteristics of the deep border, pattern of pagetoid activity) (tables 3 and 6). As previously discussed, the threshold for calling a lesion melanoma will depend on the clinical setting (ie, pretest probability). Spitzoid lesions that prompt serious consideration for a melanoma but which ultimately fall short of meeting the minimal criteria for a diagnosis of melanoma should be diagnosed as atypical Spitz tumour (high grade). Typically, a Spitzoid melanoma will exhibit an irregular pattern of growth which either disrupts or over-runs an existing organised Spitzoid silhouette or which appears completely irregular with no underlying organisation. ${ }^{86} 95120$ Occasionally, the disruption may occur as an expansile dermal nodule which often shows a different cytomorphology and mitotic rate compared with the background lesion. Extension of a Spitzoid lesion into the subcutaneous tissue is also an unusual feature, but not unheard of for Spitz naevi. Numerous mitoses including deep dermal forms and severe cytological atypia with macronucleoli are features favouring a Spitzoid melanoma. A clear-cut lack of architectural and cytological maturation is a more reliable feature for Spitzoid melanoma. Spitzoid melanomas should exhibit underlying characteristic Spitzoid architectural and/or cytomorphologcal features that define Spitzoid lesions in general.

Two paths generally lead a pathologist into the differential diagnosis of a Spitzoid melanoma: (1) removal of a lesion suspected to be a Spitzoid lesion (eg, red-brown nodule from the face of a child), which subsequently shows high-grade features; (2) histopathological appreciation of Spitzoid architectural and cytological features in a lesion in the absence of a suggestive clinical history (eg, often the manner in which Spitz naevi in adults come to light). In the former setting, the burden of diagnosis is typically on assessing the atypicality of the lesion (ie, placement of the lesion on the Spitzoid spectrum), and thus proceeds in a manner that identifies and grades atypical features with appreciation of what is permitted in Spitzoid lesions. In the latter setting, the burden of diagnosis is often placed on ensuring that one is dealing with a Spitzoid lesion (ie, not a melanoma with potentially misleading Spitzoid features), and so features such as pagetoid spread, cytological atypia and occasional superficial mitoses, which may be acceptable in a classic Spitzoid lesion taken from a child, may be more reflective of a malignant lesion in an adult, calling into question the true Spitzoid nature of the lesion. This is not a trivial distinction, since Spitzoid melanomas removed from children show a more favourable outcome even in the presence of SLN metastases. ${ }^{114} 116117$ This favourable outcome has not been noted for melanomas with Spitzoid morphology in adults. This difference in behaviour probably reflects a difference between the accurate recognition of what is probably a relatively indolent malignant tumour (Spitzoid melanoma), which overlaps significantly with lesions essentially lacking true malignant potential (atypical Spitz tumours), and a group mainly comprising fully malignant melanomas that are mistaken for Spitzoid melanomas because of suggestive histological features. For this reason, we prefer to reserve the term 'Spitzoid melanoma' for patients 20 years or under, and use the term 'melanoma with Spitzoid morphology' for older patients.

As previously mentioned, there are currently no established ancillary tests that definitively differentiate benign from malignant Spitzoid lesions. An increased proliferative index (Ki67 or MIB1 labelling) and a lack of maturation, as evidenced by diffuse HMB-45 staining, support a diagnosis of melanoma, but are not reliable 92120121 - a relatively low proliferative fraction (5-15\%) does not exclude a melanoma, and diffuse HMB-45 staining may occasionally be seen in benign lesions. Cytogenetic demonstration of multiple chromosomal abnormalities is consistent with a diagnosis of melanoma, ${ }^{106} 108109$ but such testing does not have strong clinical validation and is not widespread.

\section{Pigmented spindle cell naevus (of Reed)}

A characteristic subtype of Spitz naevus is the pigmented spindle cell naevus (also known as 'pigmented spindle cell naevus of Reed' or 'Reed naevus') (figure 7). Clinically, pigmented spindle cell naevi of Reed are recognised by their deep coloration, often appearing pitch black. ${ }^{32} 56$ Lesions are uniform in appearance, typically small $(<6 \mathrm{~mm})$, well-circumscribed and symmetrical. Classically, lesions occur in young adults, although children may be affected, with females affected more commonly than males. Typical location is the thigh followed by shoulder and upper arms, although lesions may be located on any skin site. Dermoscopy shows the characteristic Spitzoid sun-burst pattern. Histologically, the lesion is characteristic for its Spitzoid morphology (figure 5 and table 6), prominent pigmentation with numerous melanophages, and its horizontal orientation, often being entirely junctional, although most do reveal a limited dermal component. The benign nature of the lesion is assured through recognition of the Spitzoid nature of the lesion in conjunction with its benign silhouette (small size, sharp circumscription and good symmetry), and a lack of atypical features $^{30} 311^{122}$ (see below). In addition, pigmented spindle cell 

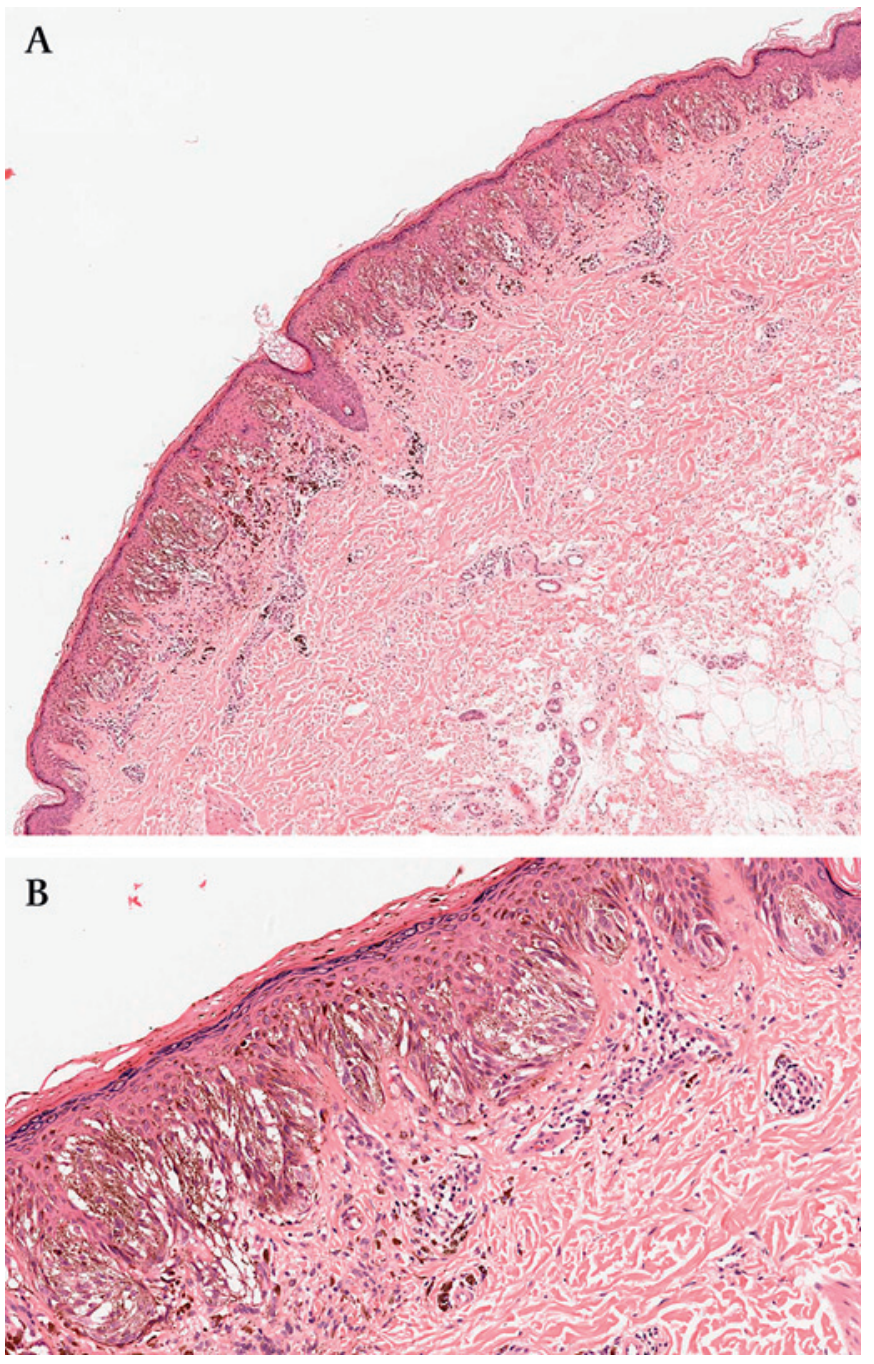

Figure 7 Junctional pigmented spindle cell naevus of Reed (36-yearold woman; forearm). (A) (H\&E; 40×) Low-power examination reveals a small heavily pigmented junctional melanocytic lesion with a Spitzoid silhouette (sharp circumscription, symmetry). Epidermal hyperplasia and vertical orientation of uniform melanocytic nests are further Spitzoid features noted. There is prominent dermal pigment incontinence, but otherwise minimal stromal reaction. (B) (H\&E; 200×) Prominent spindle cell morphology and vertical orientation of uniform nests is better appreciated. Although cells are enlarged with nucleoli, atypical nuclear features are otherwise not pronounced. Pigmentation is prominent. Rare mitoses are noted.

naevi reveal uniformity in the size and distribution of nests. As with any Spitzoid lesion, pigmented spindle cell naevi exhibit large nuclei with nucleoli often vertically oriented with epidermal hyperplasia and possible Kamino bodies. Occasional mitoses including rare dermal forms are acceptable. Pagetoid ascent of cells is often seen and, classically, in a nested rather than single cell pattern. Pigmented spindle cell naevi may show an apparent lack of maturation due to their thin nature. Lesions may also appear concerning because of their cellularity and typical rete bridging, although prominent fibroplasia is unusual. The major risk of misdiagnosis is with a superficial spreading melanoma/melanoma in situ or a Clark's naevus with high-grade features. The focus on the differential rests on recognition of the Spitzoid nature of the lesion, its small size and benign silhouette with a lack of shouldering, the uniformity of the lesion, and the lack of truly concerning features suggestive of melanoma outside of those permissible in
Spitzoid lesions (tables 3 and 6). Our practice is to consider lesions consisting of more than a small minority of epithelioid cells with features otherwise consistent with a pigmented spindle cell naevus as a pigmented variant of a Spitz naevus, granting that this differentiation is somewhat semantic.

Atypical pigmented spindle cell naevus is a term used to raise clinical concern about the biological potential of a lesion consistent with a pigmented spindle cell naevus but which demonstrates further features that are not acceptable as strictly benign. Abnormal clinical parameters (older age, changing lesion, spontaneous ulceration), larger lesions $(>1 \mathrm{~cm})$, loss of the reassuring benign silhouette, severe cytological atypia, increased mitotic activity with deep dermal or atypical forms, and expansile dermal growth represent atypical features warranting some caution in the biological potential of the lesion, and a diagnosis of atypical pigmented spindle cell naevus is appropriate. $^{31} 122$ Such lesions require complete excision with conservative margins and continued patient follow-up.

\section{CONCLUSION}

In part I, we have presented our algorithmic approach to spindle cell melanocytic lesions, one which begins with the need to recognise a spindle cell lesion as melanocytic in nature. Cytological, architectural and immunohistochemical features of melanocytic lesions are discussed to facilitate such recognition. To this end, we have also included table 1, which lists diagnostic features of non-melanocytic spindle cell cutaneous lesions that may enter into the differential diagnosis of certain spindle cell melanocytic lesions. The algorithm proceeds with a categorical subdivision of spindle cell melanocytic lesions based primarily on architectural pattern. This initial step aims to provide greater acuity when proceeding with the subsequent detailed assessment of histopathological features in an effort to predict the potential biological behaviour of the lesion. A generalised

\section{Take-home messages}

- Spindling, in its many forms, is a common phenomenon (partial or complete) that may be seen in most melanocytic lesions.

- A spindle cell morphology does not necessarily connote an aggressive biological potential and must be interpreted within the context of the type of melanocytic lesion (ie, architectural pattern) as well other histopathological and clinical features.

- Spindle cell melanocytic lesions commonly show loss of melanocyte-specific immunohistochemical markers-use of multiple specific melanotic markers increases sensitivity.

- Commonly, the histogenetic origin of a spindle cell melanocytic lesion may be determined histologically by the presence of a more recognisable junctional component, by characteristic nesting, or by an admixed pigmented/epithelioid component.

- Optimal assessment of the biological capacity of spindle cell melanocytic lesions requires a gestalt impression of numerous features (clinical, histological, ancillary studies), which should proceed in a standard way but with acceptances made for lesional patterns that characteristically express certain, otherwise, concerning features.

- The pathology report should relay to the clinician information about the histogenetic nature of the lesion as well as its potential for aggressive biological behaviour in a manner that facilitates optimal management decisions. 


\section{Interactive multiple choice questions}

This JCP review has an accompanying set of multiple choice questions (MCOs). To access the questions, click on BMJ Learning: Take this module on BMJ Learning from the content box at the top right and bottom left of the online article. For more information please go to: http://jcp.bmj.com/education Please note: the MCOs are hosted on BMJ Learning - the best available learning website for medical professionals from the BMJ Group. If prompted, subscribers must sign into JCP with their journal's username and password. All users must also complete a onetime registration on BMJ Learning and subsequently log in (with a BMJ Learning username and password) on every visit.

approach to grading the biological potential of melanocytic lesions is also provided. The final step is the application of diagnostic terminology. We strive to use established and communicative diagnostic terms that describe the histogenesis of the lesion, and at the same time optimally facilitating subsequent clinical management by reflecting an estimate of the biological risk posed by the lesion based on the assessment of the pathological and clinical parameters. Finally, we have begun our discussion of spindle cell melanocytic entities by covering those entities that fall under our first two categories: compound naevoidal pattern lesions and Spitzoid lesions. Continuing in part II, we proceed with a discussion of spindle cell melanocytic entities that fall under the final two categories: intradermal proliferations and horizontally oriented lesions. We also discuss combined lesions and provide summary thoughts.

Competing interests None.

Provenance and peer review Not commissioned; not externally peer reviewed.

\section{REFERENCES}

1. Trotter MJ, Bruecks AK. Interpretation of skin biopsies by general pathologists: diagnostic discrepancy rate measured by blinded review. Arch Pathol Lab Med 2003;127:1489-92.

2. Troxel DB. Medicolegal aspects of error in pathology. Arch Pathol Lab Med 2006;130:617-19.

3. Troxel DB. An insurer's perspective on error and loss in pathology. Arch Pathol Lab Med 2005:129:1234-6.

4. van Dijk MC, Aben KK, van Hees F, et al. Expert review remains important in the histopathological diagnosis of cutaneous melanocytic lesions. Histopathology 2008; 52:139-46.

5. High WA. Malpractice in dermatopathology: principles, risk mitigation, and opportunities for improved care for the histologic diagnosis of melanoma and pigmented lesions. Clin Lab Med 2008:28:261-84, vii.

6. Banerjee SS, Harris M. Morphological and immunophenotypic variations in malignant melanoma. Histopathology 2000;36:387-402.

7. Levene A. On the histological diagnosis and prognosis of malignant melanoma. J Clin Pathol 1980;33:101-24.

8. Jonjic N, Zamolo G, Stifter S, et al. Cytomorphological variations, proliferation and angiogenesis in the prognosis of cutaneous melanoma. Clin Exp Dermatol 2003;28:310-14

9. Lodding P, Kindblom LG, Angervall L. Metastases of malignant melanoma simulating soft tissue sarcoma. A clinico-pathological, light- and electron microscopic and immunohistochemical study of 21 cases. Virchows Arch A Pathol Anat Histopathol 1990;417:377-88.

10. Elder DE, Xu X. The approach to the patient with a difficult melanocytic lesion. Pathology 2004;36:428-34.

11. Murali R, McCarthy SW, Scolyer RA. Blue nevi and related lesions: a review highlighting atypical and newly described variants, distinguishing features and diagnostic pitfalls. Adv Anat Pathol 2009;16:365-82.

12. Ruiter DJ, van Dijk MC, Ferrier CM. Current diagnostic problems in melanoma pathology. Semin Cutan Med Surg 2003;22:33-41.

13. $\mathbf{X u} \mathbf{X}$, Elder DE. A practical approach to selected problematic melanocytic lesions. Am J Clin Pathol 2004;121(Suppl):S3-32.

14. Kamil ZS, Tong LC, Habeeb AA, et al. Non-melanocytic mimics of melanoma: part I: intraepidermal mimics. J Clin Pathol 2009;62:120-7.

15. Tong LC, Kamil ZS, Al Habeeb A, et al. Non-melanocytic mimics of melanoma, part II: intradermal mimics. J Clin Pathol 2009:62:290-307.
16. Culpepper KS, Granter SR, McKee PH. My approach to atypical melanocytic lesions. J Clin Pathol 2004;57:1121-31.

17. Magro CM, Crowson AN, Mihm MC. Unusual variants of malignant melanoma. Mod Pathol 2006;19(Suppl 2):S41-70.

18. Barnhill RL, Argenyi Z, Berwick M, et al. Atypical cellular blue nevi (cellular blue nevi with atypical features): lack of consensus for diagnosis and distinction from cellular blue nevi and malignant melanoma ("malignant blue nevus"). Am J Surg Pathol 2008;32:36-44

19. Crowson AN, Mihm MC, Magro CM. The melanocytic proliferations: a comprehensive textbook of pigmented lesions. New York: Wiley-Liss, 2001.

20. Barnhill RL, Piepkorn M, Busam KJ. Pathology of melanocytic nevi and malignant melanoma. 2nd edn. New York: Springer, 2003.

21. Mooi WJ, Krausz T, Mooi WJ. Pathology of melanocytic disorders. 2nd edn. London: Hodder Arnold, 2007.

21a. Sade S, Al Habeeb A, Ghazarian G. Spindle cell melanocytic lesions: part II - an approach to intradermal proliferations and horizontally-orientated lesions. J Clin Pathol. In press.

22. Lai K, Conway RM, Crouch $\mathrm{R}$, et al. Expression and distribution of MMPs and TIMPs in human uveal melanoma. Exp Eye Res 2008;86:936-41.

23. Tuominen $\mathbf{H}$, Kallioinen $\mathbf{M}$. Increased tenascin expression in melanocytic tumors. J Cutan Pathol 1994;21:424-9

24. Stenback F, Makinen MJ, Jussila T, et al. The extracellular matrix in skin tumor development-a morphological study. J Cutan Pathol 1999:26:327-38.

25. Weiss SW, Goldblum JR, Enzinger FM. Enzinger and Weiss's soft tissue tumors. 5th edn. St. Louis, MO: Mosby/Elsevier, 2008.

26. Wick MR. Diagnostic histochemistry. Cambridge ; New York: Cambridge University Press, 2008

27. Hornick JL, Fletcher CD. PEComa: what do we know so far? Histopathology 2006; $48: 75-82$

28. Morgan MB, Purohit C, Anglin TR. Immunohistochemical distinction of cutaneous spindle cell carcinoma. Am J Dermatopathol 2008;30:228-32.

29. Folpe AL, Cooper K. Best practices in diagnostic immunohistochemistry: pleomorphic cutaneous spindle cell tumors. Arch Pathol Lab Med 2007;131:1517-24.

30. Lever WF, Elder DE. Lever's histopathology of the skin. 10th edn. Philadelphia: Wolters Kluwer Health/Lippincott Williams \& Wilkins, 2009.

31. Barnhill RL. Textbook of dermatopathology. 2nd edn. New York: McGraw-Hill, Medical Publication Division, 2004

32. McKee PH, Calonje E, Granter SR. Pathology of the skin: with clinical correlations 3rd edn. Edinburgh: Elsevier Mosby, 2005.

33. Sternberg SS. Histology for pathologists. 2nd edn. Philadelphia: Lippincott-Raven, 1997

34. Goovaerts G, Buyssens N. Nevus cell maturation or atrophy? Am J Dermatopathol 1988; 10:20-7.

35. Winnepenninckx $\mathbf{V}$, van den Oord JJ. Immunophenotype and possible origin of nevi with phenotypical heterogeneity. Arch Dermatol Res 2004;296:49-53.

36. Mete 0, Bilgic B, Buyukbabani N. A tumor with many faces: metastatic malignant melanoma with extensive cartilaginous differentiation. Int J Surg Pathol. Published Online First: 16 Feb 2010

37. Ohsie SJ, Sarantopoulos GP, Cochran AJ, et al. Immunohistochemical characteristics of melanoma. J Cutan Pathol 2008:35:433-44.

38. Nagasaka T, Lai R, Medeiros LJ, et al. Cyclin D1 overexpression in Spitz nevi: an immunohistochemical study. Am J Dermatopathol 1999;21:115-20.

39. Prieto VG, Shea CR. Use of immunohistochemistry in melanocytic lesions. J Cutan Pathol 2008;35(Suppl 2):1-10.

40. Radfar A, Stefanato CM, Ghosn S, et al. NGFR-positive desmoplastic melanomas with focal or absent S-100 staining: further evidence supporting the use of both NGFR and S-100 as a primary immunohistochemical panel for the diagnosis of desmoplastic melanomas. Am J Dermatopathol 2006;28:162-7.

41. $\mathbf{X u} \mathbf{X}$, Zhang PJ, Elder DE. Tyrosinase expression in malignant melanoma, desmoplastic melanoma, and peripheral nerve tumors. Arch Pathol Lab Med 2003:127:1083-4; author reply 1084-5.

42. $\mathbf{X u ~ X}$, Chu AY, Pasha TL, et al. Immunoprofile of MITF, tyrosinase, melan-A, and MAGE-1 in HMB45-negative melanomas. Am J Surg Pathol 2002;26:82-7.

43. Wilsher M, Cheerala B. WT1 as a complementary marker of malignant melanoma: an immunohistochemical study of whole sections. Histopathology 2007;51:605-10.

44. Torres-Cabala CA, Wang WL, Trent J, et al. Correlation between KIT expression and KIT mutation in melanoma: a study of 173 cases with emphasis on the acrallentiginous/mucosal type. Mod Pathol 2009;22:1446-56.

45. Stefanaki C, Stefanaki K, Antoniou C, et al. Cell cycle and apoptosis regulators in Spitz nevi: comparison with melanomas and common nevi. J Am Acad Dermatol 2007; 56:815-24.

46. Hilliard NJ, Krahl D, Sellheyer K. p16 expression differentiates between desmoplastic Spitz nevus and desmoplastic melanoma. J Cutan Pathol 2009;36:753-9.

47. Garrido-Ruiz MC, Rodriguez-Pinilla SM, Perez-Gomez B. WT 1 expression in nevi and melanomas: a marker of melanocytic invasion into the dermis. J Cutan Pathol. Published Online First: 22 Jul 2009. doi: 10.1111/j.1600-0560.2009.01379.x

48. Ewanowich C, Brynes RK, Medeiros L, et al. Cyclin D1 expression in dysplastic nevi: an immunohistochemical study. Arch Pathol Lab Med 2001;125:208-10.

49. Isabel Zhu Y, Fitzpatrick JE. Expression of C-kit (CD117) in Spitz nevus and malignant melanoma. J Cutan Pathol 2006;33:33-7.

50. King MS, Porchia SJ, Hiatt KM. Differentiating spitzoid melanomas from Spitz nevi through CD99 expression. J Cutan Pathol 2007;34:576-80. 
51. Bakos RM, Maier T, Besch R, et al. Nestin and SOX9 and SOX10 transcription factors are coexpressed in melanoma. Exp Dermatol. Published Online First: 21 Oct 2009. doi: 10.1111/j.1600-0625.2009.00991.x

52. Brychtova S, Fiuraskova M, Hobilkova A, et al. Nestin expression in cutaneous melanomas and melanocytic nevi. J Cutan Pathol 2007;34:370-5.

53. Klein WM, Wu BP, Zhao S, et al. Increased expression of stem cell markers in malignant melanoma. Mod Pathol 2007;20:102-7.

54. Wagner N, Panelos J, Massi D, et al. The Wilms' tumor suppressor WT1 is associated with melanoma proliferation. Pflugers Arch 2008:455:839-47.

55. Thomas AJ, Erickson CA. The making of a melanocyte: the specification of melanoblasts from the neural crest. Pigment Cell Melanoma Res 2008;21:598-610.

56. Bolognia J, Jorizzo JL, Rapini RP. Dermatology. 2nd edn. St. Louis, MO: Mosby/ Elsevier, 2008

57. Van Paesschen MA, Goovaerts G, Buyssens N. A study of the so-called neurotization of nevi. Am J Dermatopathol 1990:12:242-8.

58. Ide F, Mishima K, Yamada H, et al. Neurotized nevi of the oral mucosa: an immunohistochemical and ultrastructural analysis of nevic corpuscles. J Oral Pathol Med 2007;36:505-10.

59. $\mathbf{X u} \mathbf{X}$, Bellucci KS, Elenitsas $\mathrm{R}$, et al. Cellular nodules in congenital pattern nevi. J Cutan Pathol 2004:31:153-9.

60. Bastian BC, Xiong J, Frieden IJ, et al. Genetic changes in neoplasms arising in congenital melanocytic nevi: differences between nodular proliferations and melanomas. Am J Pathol 2002;161:1163-9.

61. Tannous ZS, Mihm MC Jr, Sober AJ, et al. Congenital melanocytic nevi: clinica and histopathologic features, risk of melanoma, and clinical management. J Am Acad Dermatol 2005:52:197-203.

62. Hosler GA, Moresi JM, Barrett TL. Nevi with site-related atypia: a review of melanocytic nevi with atypical histologic features based on anatomic site. J Cutan Pathol 2008;35:889-98.

63. Khalifeh I, Taraif S, Reed JA, et al. A subgroup of melanocytic nevi on the distal lower extremity (ankle) shares features of acral nevi, dysplastic nevi, and melanoma in situ: a potential misdiagnosis of melanoma in situ. Am J Surg Pathol 2007;31:1130-6.

64. Elder DE. Precursors to melanoma and their mimics: nevi of special sites. Mod Pathol 2006:19(Suppl 2):S4-20.

65. Boyd AS, Rapini RP. Acral melanocytic neoplasms: a histologic analysis of 158 lesions. J Am Acad Dermatol 1994;31(5 Pt 1):740-5.

66. Gleason BC, Hirsch MS, Nucci MR, et al. Atypical genital nevi. A clinicopathologic analysis of 56 cases. Am J Surg Pathol 2008;32:51-7.

67. Ribe A. Melanocytic lesions of the genital area with attention given to atypical genital nevi. J Cutan Pathol 2008;35(Suppl 2):24-7.

68. Rongioletti F, Urso C, Batolo D, et al. Melanocytic nevi of the breast: a histologic case-control study. J Cutan Pathol 2004:31:137-40.

69. Rongioletti F, Ball RA, Marcus R, et al. Histopathological features of flexural melanocytic nevi: a study of 40 cases. J Cutan Pathol 2000;27:215-17.

70. Saad AG, Patel S, Mutasim DF. Melanocytic nevi of the auricular region: histologic characteristics and diagnostic difficulties. Am J Dermatopathol 2005;27:111-15.

71. Lazova R, Lester B, Glusac EJ, et al. The characteristic histopathologic features of nevi on and around the ear. J Cutan Pathol 2005:32:40-4.

72. Fabrizi G, Pagliarello C, Parente P, et al. Atypical nevi of the scalp in adolescents. J Cutan Pathol 2007:34:365-9.

73. Jakobiec FA, Colby K, Bajart AM, et al. Immunohistochemical studies of atypical conjunctival melanocytic nevi. Arch Ophthalmol 2009;127:970-80.

74. Thiagalingam S, Johnson MM, Colby KA, et al. Juvenile conjunctival nevus: clinicopathologic analysis of 33 cases. Am J Surg Pathol 2008;32:399-406.

75. LeBoit PE. A diagnosis for maniacs. Am J Dermatopathol 2000;22:556-8.

76. Clark WH Jr, Hood AF, Tucker MA, et al. Atypical melanocytic nevi of the genital type with a discussion of reciprocal parenchymal-stromal interactions in the biology of neoplasia. Hum Pathol 1998:29(1 Suppl 1):S1-24.

77. Collina G, Reggiani C. Recurrence of nevoid melanoma originally diagnosed as benign nevus. Pathologica 2009;101:112-14.

78. Wong TY, Suster S, Duncan LM, et al Nevoid melanoma: a clinicopathological study of seven cases of malignant melanoma mimicking spindle and epithelioid cell nevus and verrucous dermal nevus. Hum Pathol 1995;26:171-9.

79. Zembowicz A, McCusker M, Chiarelli C, et al. Morphological analysis of nevoid melanoma: a study of 20 cases with a review of the literature. Am J Dermatopathol 2001;23:167-75

80. McNutt NS, Urmacher C, Hakimian J, et al. Nevoid malignant melanoma: morphologic patterns and immunohistochemical reactivity. J Cutan Pathol 1995;22:502-17.

81. Suster S, Ronnen M, Bubis JJ. Verrucous pseudonevoid melanoma. J Surg Oncol 1987; 36:134-7.

82. LeBoit PE, Burg G, Weedon D, et al. Pathology \& genetics: skin tumours. Lyon, France. IARC Press, 2006.

83. Rosner K, Mehregan DR, Moussai D, et al. WT1 marker is not sufficient for distinguishing between melanoma and melanocytic nevi. J Cutan Pathol 2009 Jul 9.

84. Yang $\mathbf{X H}, \mathrm{Wu} \mathrm{OL}, \mathrm{Yu} \mathbf{X B}$, et al. Nestin expression in different tumours and its relevance to malignant grade. J Clin Pathol 2008;61:467-73.

85. Billings TL, Barr R, Dyson S. Langerhans cell histiocytosis mimicking malignant melanoma: a diagnostic pitfall. Am J Dermatopathol 2008:30:497-9.

86. Massi G, LeBoit PE. Histological diagnosis of nevi and melanoma. Darmstadt; Berlin: Steinkopff; Springer, 2004

87. Paniago-Pereira C, Maize JC, Ackerman AB. Nevus of large spindle and/or epithelioid cells (Spitz's nevus). Arch Dermatol 1978;114:1811-23.
88. Weedon D, Little JH. Spindle and epithelioid cell nevi in children and adults. A review of 211 cases of the Spitz nevus. Cancer 1977;40:217-25

89. Arbuckle S, Weedon D. Eosinophilic globules in the Spitz nevus. J Am Acad Dermatol 1982:7:324-7.

90. Moreno A, Salvatella N, De Moragas JM. Eosinophilic globules in the Spitz nevus Med Cutan Ibero Lat Am 1984:12:91-4.

91. Requena C, Requena L, Kutzner $H$, et al. Spitz nevus: a clinicopathological study of 349 cases. Am J Dermatopathol 2009;31:107-16.

92. Paradela $\mathbf{S}$, Fonseca E, Pita $\mathbf{S}$, et al. Spitzoid melanoma in children: clinicopathological study and application of immunohistochemistry as an adjunct diagnostic tool. J Cutan Pathol 2009;36:740-52.

93. Spatz A, Calonje E, Handfield-Jones S, et al. Spitz tumors in children: a grading system for risk stratification. Arch Dermatol 1999;135:282-5.

94. Rapini RP. Spitz nevus or melanoma? Semin Cutan Med Surg 1999;18:56-63.

95. Evans AT. Spitz tumours. Diagn Histopathol 2007;14:28-37.

96. Barnhill RL. The Spitzoid lesion: rethinking Spitz tumors, atypical variants, 'Spitzoid melanoma' and risk assessment. Mod Pathol 2006;19(Suppl 2):S21-33.

97. Barnhill RL, Argenyi ZB, From L, et al. Atypical Spitz nevi/tumors: lack of consensus for diagnosis, discrimination from melanoma, and prediction of outcome. Hum Pathol 1999:30:513-20.

98. Barnhill RL. The spitzoid lesion: the importance of atypical variants and risk assessment. Am J Dermatopathol 2006:28:75-83.

99. Bron JL, Jaspars EH, Molenkamp BG, et al. Three patients with a Spitz naevus that later turned out to be a melanoma. Ned Tijdschr Geneeskd 2005;149:1852-8.

100. Murali R, Sharma RN, Thompson JF, et al. Sentinel lymph node biopsy in histologically ambiguous melanocytic tumors with spitzoid features (so-called atypical spitzoid tumors). Ann Surg Oncol 2008;15:302-9.

101. Ludgate MW, Fullen DR, Lee J, et al. The atypical Spitz tumor of uncertain biologic potential: a series of 67 patients from a single institution. Cancer 2009; 115:631-41

102. Urso C. Borgognoni L, Saieva C et al. Sentinel lymph node biopsy in patients with "atypical Spitz tumors." A report on 12 cases. Hum Pathol 2006;37:816-23.

103. Urso C, Gelli R, Borgognoni L, et al. Positive sentinel node biopsy in a 30-month-old boy with atypical Spitz tumour (Spitzoid melanoma). Histopathology 2006;48:884-6

104. Su LD, Fullen DR, Sondak VK, et al. Sentinel lymph node biopsy for patients with problematic spitzoid melanocytic lesions: a report on 18 patients. Cancer 2003;97:499-507

105. Lohmann CM, Coit DG, Brady MS, et al. Sentinel lymph node biopsy in patients with diagnostically controversial spitzoid melanocytic tumors. Am J Surg Pathol 2002; 26:47-55.

106. Bastian BC, Olshen $A B$, LeBoit PE, et al. Classifying melanocytic tumors based on DNA copy number changes. Am J Pathol 2003;163:1765-70.

107. Bastian BC, Wesselmann U, Pinkel D, et al. Molecular cytogenetic analysis of Spitz nevi shows clear differences to melanoma. J Invest Dermatol 1999;113:1065-9.

108. Gerami $\mathbf{P}$, Jewell SS, Morrison LE, et al. Fluorescence in situ hybridization (FISH) as an ancillary diagnostic tool in the diagnosis of melanoma. Am J Surg Pathol 2009:33:1146-56.

109. Carlson JA, Ross JS, Slominski AJ. New techniques in dermatopathology that help to diagnose and prognosticate melanoma. Clin Dermatol 2009:27:75-102.

110. Grichnik JM, Rhodes AR, Sober AJ. Benign neoplasias and hyperplasias of melanocytes. In: Wolff K, Goldsmith LA, Katz SI, et al. Fitzpatrick's dermatology in general medicine. 7th edn. New York: McGraw-Hill, 2008:1099-1121.

111. Cesinaro AM, Foroni M, Sighinolfi $P$, et al. Spitz nevus is relatively frequent in adults: a clinico-pathologic study of 247 cases related to patient's age. Am J Dermatopathol 2005:27:469-75

112. Skelton HG, Miller ML, Lupton GP, et al. Eosinophilic globules in spindle cell and epithelioid cell nevi: composition and possible origin. Am J Dermatopathol 1998:20:547-50.

113. Wesselmann U, Becker LR, Brocker EB, et al. Eosinophilic globules in spitz nevi: no evidence for apoptosis. Am J Dermatopathol 1998:20:551-4.

114. Busam KJ, Murali R, Pulitzer M, et al. Atypical spitzoid melanocytic tumors with positive sentinel lymph nodes in children and teenagers, and comparison with histologically unambiguous and lethal melanomas. Am J Surg Pathol 2009;33:1386-95.

115. Mones JM, Ackerman AB. "Atypical" Spitz's nevus, "malignant" Spitz's nevus, and "metastasizing" Spitz's nevus: a critique in historical perspective of three concepts flawed fatally. Am J Dermatopathol 2004;26:310-33.

116. Busam KJ, Pulitzer M. Sentinel lymph node biopsy for patients with diagnostically controversial spitzoid melanocytic tumors? Adv Anat Pathol 2008:15:253-62.

117. Pol-Rodriquez $\mathbf{M}$, Lee S, Silvers DN, et al. Influence of age on survival in childhood spitzoid melanomas. Cancer 2007;109:1579-83.

118. Dawe RS, Wainwright NJ, Evans AT, et al. Multiple widespread eruptive Spitz naevi. Br J Dermatol 1998;138:872-4.

119. Harvell JD, Bastian BC, LeBoit PE. Persistent (recurrent) Spitz nevi: a histopathologic, immunohistochemical, and molecular pathologic study of 22 cases. Am J Surg Pathol 2002;26:654-61.

120. Kamino H. Spitzoid melanoma. Clin Dermatol 2009;27:545-55.

121. Kapur P, Selim MA, Roy LC, et al. Spitz nevi and atypical Spitz nevi/tumors: a histologic and immunohistochemical analysis. Mod Pathol 2005;18:197-204.

122. Barnhill RL, Barnhill MA, Berwick $M$, et al. The histologic spectrum of pigmented spindle cell nevus: a review of 120 cases with emphasis on atypical variants. Hum Pathol 1991;22:52-8. 